DIVISION OF THE HUMANITIES AND SOCIAL SCIENCES

CALIFORNIA INSTITUTE OF TECHNOLOGY

PASADENA, CALIFORNIA 91125

INTRADAY TRADE IN DEALERSHIP MARKETS

Dan Bernhardt

Queen's University

Eric Hughson

California Institute of Technology

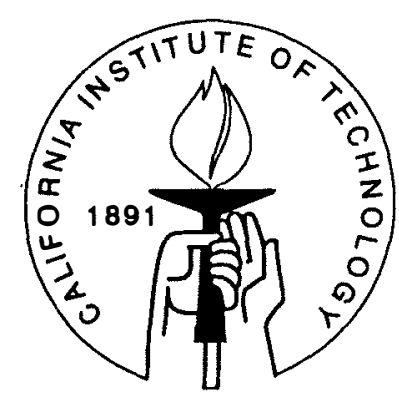




\title{
INTRADAY TRADE IN DEALERSHIP MARKETS
}

\author{
Dan Bernhardt $\quad$ Eric Hughson*
}

\begin{abstract}
We develop and test a structural asymmetric information transaction model to characterize the price impact of information when markets are thin. Since orders are accepted individually, the model allows for transaction costs and brokerage fees. Equilibrium demands mixed entry strategies on the part of potentially-informed traders. Estimation of the structural parameters is performed using a maximum likelihood procedure on NYSE data. The price impact of information is found to be positive and significant, but economically small. This is because while the amount of private information is substantial, the quality of the information signals is quite poor. Insiders do not trade small quantities, which suggests that their ability to divide orders is limited by transaction costs.
\end{abstract}

*We wish to thank Richard Green, David Marshall, Robert Miller, Ken Singleton, Chester Spatt, John Piazza, a former specialist on the American Stock Exchange, for valuable guidance and discussions in the formulation of this problem. 


\section{Introduction}

This paper develops and tests an asymmetric information market transaction model to explain the price and volume moments that characterize intraday transaction-by-transaction trade on the NYSE. We model the fact that intraday transactions on the NYSE are temporally dispersed and that most such trades are completed independently. Thin markets imply that potentially-informed speculators must adopt mixed information acquisition/entry strategies in equilibrium. Thin intraday markets also lead the specialist's pricing function to be invariant to fluctuations in expected volume. Because spreads can also arise due to transaction costs, we consider the possibility that the specialist or dealer incurs both fixed and variable costs when completing transactions.

In contrast to previous literature where trades are necessarily pooled (e.g. Kyle [1985], Admati and Pfleiderer [1988]), characterization of the equilibrium yields explicit implications for transaction-by-transaction behavior as a function of the model's structural parameters during the trading day. A further advantage of the transaction-by-transaction formulation is that it can allow for transaction costs and brokerage fees. We use the Fitch transaction-bytransaction NYSE price and volume data to test the model. In contrast to the previous literature (e.g. Cilosten and Harris [1989], Hasbrouck [1991]), rather than estimate the reduced form price impact of information, we estimate the structural parameters which comprise the price impact. We exploit the nonlinear restrictions provided by the model to estimate the probability that the specialist faces an informed trader, the amount and quality of inside information, the cost of information acquisition, and transaction costs.

Neither ordinary nor generalized least squares are efficient estimation procedures even when bid-ask indicators are observable, much less imputed from quote data as in Lee and Ready [1991]. This is because mixed entry strategies on the part of the potentially-informed imply that price changes and traded "quantities are conditionally but not unconditionally normally distributed. The mixed unconditional distribution for volume helps identify the probability that a particular trader is informed. Given the restrictions of our model the efficient estimation procedure maximizes the joint likelihood function for price and volume.

Empirically, we find that the price impact of information is positive and significant. However, 
this impact is economically unimportant for small orders. Even for large orders, the tariff is only on the order of the bid-ask spread. The price impact of information appears to vary throughout the day, but it does not necessarily match the U-shaped volume pattern found in previous research (e.g. Wood, McInish and Ord [1985]). It is, however, highest near the open and close. The reason for the low price impact of information does not appear to be a lack of information coming to the market in the intraday period - the magnitude of the informational innovations appears to be larger than the bid-ask spread. Rather, the signals that the informed traders receive are very noisy, particularly in the middle of the day. Variations in the price impact of information appear to be caused not so much by intradaily fluctuations in the amount of inside information, as by fluctuations in the quality of information.

Insiders are found to trade far greater quantities than uninformed traders, up to 20 times larger. This suggests that the fixed costs of trading are high enough relative to the price impact of information to make splitting orders unattractive.

As a consequence, we then integrate trasaction costs in to the model. The transaction costs formulation precludes identification of some of the structural parameters, but both a per share transaction cost and a quantity cutoff below which insiders will not trade (so there is no adverse selection ) can be estimated. The resulting equilibrium pricing function is kinked. We reject the linear pricing rule in favor of the kinked rule.

Estimation of the pricing relationship for NYSE stocks beyond linear pricing requires that the model incorporate the thin nature of the market. Terry [1986] shows that during the day there are often long intervals when no transaction occurs ${ }^{1}$, and that consecutive trades are generally sufficiently separated temporally. Bronfman [1990] notes that trades are accepted independently, even when volume is very heavy - e.g. 5000 trades per day: ${ }^{2}$ intraday transactions are almost never pooled on the NYSE.

\footnotetext{
${ }^{1}$ He finds that the average time between trades for stocks on the Dow 30 and for all NYSE stocks are 2.7 and 15.2 minutes respectively on December 31, 1989. Further, since these averages are (total trading minutes)/(total number of firms), the weight to the heavily traded stocks is proportionally greater. Terry also provides an equally weighted average for the Dow 30 - an average of 4.3 minutes between trades.

${ }^{2}$ USX volume on 23 October 1989.
} 
In models such as those of Admati and Pfleiderer [1988], or Foster and Viswanathan [1988], which restrict potentially-informed agents to pure strategies, an equilibrium with insider trading only exists when informed traders transact each period. Consequently, the market must always be sufficiently thick that each period the (necessarily) multiple transactions of informed and uninformed traders can be pooled together to obtain one net transaction price. The predictions of this class of models differ crucially from the model here. In particular, they predict that the specialist's pricing function fluctuates with expected volume. This precludes the possibility of estimation because of the substantial systematic and unsystematic variation in intraday volume. In contrast, when the thin nature of the market is modeled explicitly, the resulting equilibrium pricing function is invariant to fluctuations in expected volume, even when transaction costs are incorporated. It is this invariance which allows estimation.

The reason for this invariance, is that when markets are thin, potentially-informed traders randomize their decisions to acquire information and trade. In equilibrium, a potentiallyinformed agent who adopts a randomized strategy must be indifferent a.bout whether or not to acquire information: he must expect zero profits net of information costs. To effect this outcome, the sampling probabilities of the informed must be perfectly correlated with the arrival rate of liquidity traders.

Because each transaction is met individually, we can consider the possibility that the market makers incur both a fixed fee and a per-share cost to completing each individual transaction. If there are transaction costs, a pooling model is inappropriate because buyers and sellers may be charged different prices. In addition, the number of trades affects transaction costs, since, when there is a fixed fee, additional costs are incurred if a large order is split into smaller ones. With fixed transaction costs, small trades contain no information about the asset innovation so that there is no adverse selection for such trades. Insiders do not trade small quantities because the transaction costs exceed the expected profits derived from their information. For larger orders, an adverse selection component to the specialist's pricing function exists, but is smaller than it would be in the absence of these costs. The greater the fraction of the expected trading costs (information acquisition and fixed transacting costs) incurred by the informed which are transaction costs, the flatter is the specialist's pricing function, the greater the transaction 
volume level below which informed agents do not transact, and the less likely an agent is to seek inside information. Finally, the transaction costs induce the negative serial correlation in the price series observed in NYSE data.

\section{The model}

Consider a market run by a risk neutral specialist. During a day of $T$ periods the market is open from period $T_{0}$ until period $T, 1<T_{0}<T$. A new day starts immediately after the previous day's close. We characterize trade in the intraday trading periods $T_{0}+1$ to $T-1$ : At open and close, different market clearing mechanisms which involve pooling of transactions operate, so that an assumption that simultaneous transactions are handled independently is inappropriate (see Stoll and Whaley [1990]). Under weak regularity conditions (see Bernhardt and Hughson [1992a]), liquidity traders who can choose when to trade only trade at open and close. Hence we restrict our attention in the intraday markets to two types of risk neutral traders: uninformed liquidity traders who trade a fixed (stochastic) quantity in a fixed period, and potentially informed traders who can pay a cost to acquire inside information.

These agents trade claims to a risk free asset with single period gross return $r$ and a single risky asset whose value in period $\tau$ is given by:

$$
F_{\tau}=r^{\tau} F_{0}+\sum_{t=1}^{\tau} r^{\tau-t} \delta_{t} H_{t},
$$

where $\delta_{t}$, the informational innovation is a normal independently distributed random variable with zero mean and variance $v_{t}$, and $H_{t}$ is an indicator function which is equal to one if there is an innovation in period $t$ and is equal to zero otherwise. When innovations are infrequent, trades would cluster around informational events, because the informed would only trade then. The probability of an innovation in any given period is given by $\gamma . F_{0}$ is the liquidation value of the asset at the end of the previous trading day, and includes (discounted) any future deterministic component of the firm. $F_{T}$ is the liquidation value after the current trading day's close. Both $F_{0}$ and $F_{T}$ can be interpreted as common perceptions of the value of the risky asset at those moments. The impact of the risk-free rate on the intraday evolution of price moments is shown to be small in Bernhardt and Hughson [1992a] because the entire risk-free return is earned overnight, so we set $r=1$ to reduce the notational burden. 
On the NYSE, the actual receipt of securities is invariant to the intraday timing of trades. At each moment in a day agents trade claims to the risky asset whose value is given by its worth at close. The value in period $\tau$ of these claims is given by

$$
V_{\tau}=E_{\tau}\left[V_{T}\right]=F_{0}+\sum_{t=1}^{\tau} \delta_{t} H_{t}
$$

In period $t, F_{t-1}$ is common knowledge, so that uncertainty about the risky asset's time $t$ value only concerns whether there was an innovation in period $t$, and if so, its value, $\delta_{t}$. Thus, information is only good for one period.

Liquidity (noise) traders arrive at the market in period $t$ according to an independently distributed stochastic process with mean arrival rate $\eta_{t}$ and positive variance. Noise trader $k$ cannot be distinguished as uninformed. He has inelastic demand, $z_{k t}$, which is the realization of an independently and identically distributed normal random variable with zero mean and variance $\sigma$. The parameter $\eta_{t}$ is a measure of market depth - when $\eta_{t}$ is small, there is little background trading noise in which an informed agent can hide.

Each period $t$ there are $\mathcal{N}_{t}$ potentially-informed traders. Potentially-informed trader $i$ can pay a cost $c$ to attempt to find inside information about an innovation in $t$. If an innovation occurs in $t$, he receives a private signal about its value, $\delta_{t}+\epsilon_{i t}$, where $\epsilon_{i t}$ is an independently and identically distributed normal random variable with zero mean and variance $\phi$. Since, in period $t+1, \delta_{t}$ becomes common knowledge, this information is valuable to trader $i$ only in period $t$. If there is no innovation, the information acquisition investment is wasted.

Given his signal $\delta_{t}+\epsilon_{i t}$ agent $i$ selects a demand, $x_{i t}^{*}\left(\delta_{t}+\epsilon_{i t}\right)$, to maximize expected profits:

$$
M A X_{x_{i t}} E\left[x_{i t}\left[F_{t}-p_{t}^{*}\left(x_{i t}\right)\right] \mid \delta_{t}+\epsilon_{i t}\right]
$$

conditional on his signal. The probability of acquiring a signal, $\pi_{i t}^{*}$, maximizes his expected profits within that period given his subsequent profit-maximizing demand if informed:

$$
M A X_{\pi_{i t}} E\left[\pi_{i t}\left[M A X_{x_{i t}}\left[E\left[H_{t} x_{i t}^{*}\left[F_{t}-p_{t}^{*}\left(x_{i t}^{*}\right)\right] \mid \delta_{t}+\epsilon_{i t}, H_{t}\right]-c\right]\right]\right] .
$$

The market is made by a specialist and many floor traders. In accord with practice on the NYSE, we assume that orders received by the market makers during the intraday trading period are 
handled independently ${ }^{3}$ so that the price schedule is updated after nearly every trade.

In the intraday trading periods, market makers are essentially indistinguishable. A market maker selects his pricing function taking into account the subsequent strategic response of the potentially-informed traders. Each period, he first selects a linear pricing function which details for each possible transaction level, the price at which the market maker is willing to transact. Agents then look at the price schedule and decide whether to become informed and/or trade. Risk neutrality ${ }^{4}$ and competition together imply that the identity of the agent who takes the opposite side of each order is irrelevant.

An uninformed risk-neutral market maker selects his pricing function taking into account the subsequent strategic response of the traders. A market maker does not know the identity of the agent with whom he transacts (informed or uninformed). Therefore, the common price schedule offered by the dealers is such that they earn zero expected profits ex-ante:

$$
E_{H_{t}, \mathcal{S}_{t}}\left[\omega_{t}^{*}\left[F_{t}-p_{t}^{*}\left(\omega_{t}^{*}\right)\right]\right]=0
$$

for all $t$, where $\omega_{t}^{*}$ equals $x_{t}^{*}$ if the trader is informed and $z_{t}$ otherwise.

\section{Equilibrium}

An equilibrium is a pricing function $p_{t}^{*}\left(\omega_{t}\right)$; a set of sampling probabilities $\left\{\pi_{i t}^{*}\right\}, i=$ $1, \ldots, \mathcal{N}_{t}, \pi_{i t}^{*} \in[0,1]$; an associated set of demands for the risky asset by the potentially informed agents $\left\{x_{i t}^{*}\left(\delta_{t}+\epsilon_{i t}\right)\right\}$; for all $t$ such that given $p_{t}^{*}\left(\omega_{t}\right)$,

\footnotetext{
${ }^{3}$ We think of each period lasting only a couple of minutes, so that multiple orders in the same period are unlikely. In the unlikely' event of multiple orders, the market makers do not condition their price schedule on the number of traders in the market.

${ }^{4}$ For securities where the specialist handles only a small fraction of trades in a stock, inventory cost models may' be difficult to estimate. Since a market maker is relatively free to pick and choose which transactions to take, it is straightforward for him to keep a balanced portfolio. In equilibrium, the market maker who takes a transaction is likely to be the one who benefits most from the resulting rebalancing - and hence offers the most attractive price. One might even expect the inventory cost component to the bid-ask spread to be negative on occasion. This may explain the weak inventory effects found by Madhavan and Smidt [1992], and Hasbrouck and Sofianos [1992]. For securities where the specialist completes most trades, an inventory cost model might be estimable, although our competitivity assumption would be violated.
} 
1. If agent $i$ is informed, he selects his demand, $x_{i t}^{*}\left(\delta_{t}+\epsilon_{i t}\right)$, to maximize expected profits:

$$
M A X_{x_{i t}} E\left[x_{i t}\left[F_{t}-p_{t}^{*}\left(x_{i t}\right)\right] \mid \delta_{t}+\epsilon_{i t}\right]
$$

2. The probability that potentially-informed agent chooses to become informed, $\pi_{i t}^{*}$, maximizes expected profits given his subsequent behavior if informed,

$$
M A X_{\pi_{i t}} E\left[\pi_{i t}\left[M A X_{x_{i t}} E\left[H_{t} x_{i t}^{*}\left[F_{t}-p_{t}^{*}\left(x_{i t}^{*}\right)\right] \mid \delta_{t}+\epsilon_{i t}, H_{t}\right]-c\right]\right] \text {. }
$$

3. The informed traders earn zero expected profits in equilibrium.

$$
E_{\delta_{t}+\epsilon_{i t}}\left[\pi_{i t}\left[M A X_{x_{i t}}\left[E_{x_{i t}, \delta_{t}, \epsilon_{i t}}\left[H_{t} x_{i t}^{*}\left[F_{t}-p_{t}^{*}\left(x_{i t}^{*}\right)\right] \mid \delta_{t}+\epsilon_{i t}, H_{t}\right]-c\right]\right]\right]=0 .
$$

4. The market maker accepting the order earns zero expected profits transaction-by-transaction (but not necessarily transaction-size-by-transaction-size)

$$
E\left[\omega_{t}^{*}\left(F_{t}-p_{t}^{*}\left(\omega_{t}^{*}\right)\right)\right]=0 \quad \forall t
$$

Given each agent's time $t$ information set and the optimal strategies of all other agents, each agent maximizes his expected profits, and the dealer earns zero expected profits each period.

\subsection{The period problem}

In the period problem, we first determine the specialist's pricing function. The specialist adopts a linear pricing rule, $p_{t}=F_{t-1}+\lambda_{t} \omega_{t}$, for the risky asset which yields him zero expected profits conditional on the orders he meets. Given this pricing rule, we then determine the equilibrium sampling and trading probabilities for the traders, and the demands of the informed. To reduce notation we suppress the time subscripts.

An agent who has paid a cost $c$ to become informed solves:

$$
M A X_{x_{i}} E\left[x_{i}(\delta-\lambda \omega) \mid \delta+\epsilon_{i}\right]
$$

Since intraday transactions are accepted independently, the informed agent knows that volume, $\omega$, consists only of his own demand, $x_{i}$, and substitutes for $\omega$ in (1). Differentiating with respect to $x_{i}$ and applying the projection theorem yields:

$$
x_{i}=\frac{v\left(\delta+\epsilon_{i}\right)}{2 \lambda(v+\phi)}=\beta\left[\delta+\epsilon_{i}\right] .
$$


where

$$
\beta=\frac{v}{2 \lambda(v+\phi)} .
$$

Since $\pi$ is the probability a trader attempts to acquire information and $\gamma$ is the probability of an informational event, let $\theta=\frac{\pi \gamma}{\eta+\pi \gamma}$ be the probability from the market maker's perspective that a given trader is informed. The market maker's zero expected profit condition requires that he equate expected losses to the informed to the expected gains from trading with the uninformed:

$$
\theta E\left[\beta\left[\delta+\epsilon_{i}\right]\left[\delta-\lambda \beta\left[\delta+\epsilon_{i}\right]\right]\right]=[1-\theta] E(z \lambda z) .
$$

Taking the unconditional expectation of both sides and solving for $\lambda$ yields:

$$
\lambda=\frac{\theta \beta v}{\theta \beta^{2}(v+\phi)+(1-\theta \sigma)}
$$

Substituting for $\beta$ and solving for $\lambda$ yields:

$$
\lambda=\frac{v \sqrt{\theta}}{2 \sqrt{(v+\phi)(1-\theta \sigma)}} .
$$

This implies that:

$$
\beta=\sqrt{\frac{1-\theta \sigma}{\theta(v+\phi)}} .
$$

The expected number of informed can be found by equating the expected profits of the informed with the acquisition cost, $c$. The market makers' zero profit condition implies that his expected losses to the informed, $\frac{\theta c}{\gamma}$, must equal his expected profits from the noise traders, $\frac{1-\theta}{\lambda \sigma}$ :

$$
(1-\theta) \lambda \sigma=\frac{\theta c}{i} . \text { or: } \eta \lambda \sigma=\pi c,
$$

when we substitute for $\pi$ and $\eta$. Substituting for $\lambda$ and solving yields:

Proposition 1 The probability that the market maker trades with an informed agent in period $t \in\left(T_{\mathbf{0}}, T\right)$, given there is a transaction is given by:

$$
\theta_{t}=\frac{\gamma^{2} \sigma v^{2}}{\gamma^{2} \sigma v^{2}+4 c^{2}(v+\phi)}
$$

The linear coefficients of the market maker's pricing function and an informed agent's demand function are given by

$$
\lambda=\frac{\gamma v^{2}}{4 c(v+\phi)} ; \quad \beta=\frac{2 c}{v \gamma}
$$


Observe that as sampling costs fall, the conditional probability that the market maker faces an informed trader increases. As sampling costs become arbitrarily large, or the probability of an event becomes arbitrarily small, the probability of meeting an informed trader goes to zero.

The expected number of potential traders that become informed is given by:

$$
\pi=\frac{\gamma \sigma v^{2} \eta}{4 c^{2}(v+\phi)}
$$

The equilibrium pricing function is invariant to the number of potential intermediaries when intraperiod trades are accepted individually. There are multiple equilibria in the following sense: Only the expected number of informed agents is identified by the market maker's zero profit conditions. Because of the linearity of the price schedule and its invariance to the actual number of arrivals within a period, the market maker's expected profits are unaffected by how expected entry is divided among the potentially-informed. Bernhardt and Hughson [1992a] show that standard equilibrium refinements select the equilibrium with a single potentiallyinformed trader. We therefore focus on this equilibrium, so that $\pi$ becomes the probability of informed trade.

The pricing function, $\lambda$, in (10) is independent of the aggregate variance of liquidity trade, $\sigma$. This result differs markedly from that in Admati and Pfleiderer, whose equilibrium $\lambda$ is decreasing in $\sigma$. Notice that here, the probability of informed entry, $\pi$, is linear in $\sigma$. The market maker's profits from the uninformed are also linear in $\sigma$ : the two effects exactly offset each other. This invariance occurs in markets which are too thin for Admati and Pfleiderer's equilibrium to exist. The non-existence of pure strategy equilibria when markets are too thin to support the constant presence of an insider follows because when insiders are absent the specialist should not set a positive bid-ask spread, but then this would draw insiders....

\subsection{Transaction costs and brokerage fees}

Suppose agents now face an additional tariff to execute their trades, $c_{1}|\omega|+c_{2}$, where $c_{1}$ is a per-share transaction cost paid to the market maker and $c_{2}$ is a deadweight cost incurred if the trade is executed. We consider this alternative specification to bring the model into rough conformity with the data. If $c_{1}$ is positive, the transaction price series exhibits the negative serial correlation that is observed in NYSE data. One can think of $c_{2}$ as the (unmodeled) 
opportunity cost of the potentially informed agent's time. Thus, $c_{1}$ is incorporated directly in the transaction price recorded on the Fitch tapes, while $c_{2}$, the deadweight cost, is not. ${ }^{5}$ Hence, $c_{1}$ is essentially half the bid-ask spread (see e.g. Roll [1984]).

In addition to determining whether to obtain information, the potentially-informed must also determine whether it is optimal to trade given the signal obtained. The ex-ante expected fixed costs to entry faced by a potentially-informed trader (which include $c$, the cost of information acquisition) become:

$$
c^{*}=c+2 c_{2}\left[1-\Phi(\delta+\epsilon)^{*}\right]
$$

where $\Phi(\delta+\epsilon)^{*}$ is the cumulative distribution function for a normal random variable with zero mean and variance $v+\phi$, and $2\left[1-\Phi(\delta+\epsilon)^{*}\right]$ is the probability that an informed trader receives a signal sufficiently "large" that he expects profits from trade which exceed the transactions costs. This then is the probability that he actually trades given that he is informed. The market maker's conjectured pricing function is:

$$
\begin{array}{ll}
P_{t}=F_{t-1}+\lambda_{t} \omega_{t}+c_{1} & \text { if } \omega_{t} \geq \omega(\delta+\epsilon)^{*}, \\
P_{t}=F_{t-1}+c_{1} & \text { if } 0 \leq \omega_{t}<\omega(\delta+\epsilon)^{*}, \\
P_{t}=F_{t-1}-c_{1} & \text { if }-\omega_{t}(\delta+\epsilon)^{*} \leq \omega_{t}<0, \\
P_{t}=F_{t-1}-\lambda_{t} \omega_{t}-c_{1} & \text { if } \omega_{t}<-\omega(\delta+\epsilon)^{*},
\end{array}
$$

where $\omega(\delta+\epsilon)^{*} \equiv \omega^{*}$ is the critical trading quantity and $\left|(\delta+\epsilon)^{*}\right|$ is the associated maximum signal below which no adverse selection problem exists. For small trading quantities, the profits an that informed agent expects from his information are exceeded by his transaction (and/or brokerage) fees. For signals which would lead to such trades, it is not profitable for the informed trader to exploit his limited private information.

The market maker expects zero profits net of transaction costs for any trade. For small trades, there is no adverse selection since the informed do not trade such small quantities. Glosten and Harris [1989] attempt to distinguish econometrically the transaction cost components, but their formulation does not recognize that when information is costly to obtain,

\footnotetext{
${ }^{5}$ This specification is chosen in part for tractability. It also builds on Glosten and Harris [1989] who do not find a fixed transaction cost to be significantly different from zero.
} 
the adverse selection problem vanishes for small transaction quantities. This may lead them to underestimate the price impact of information. Here, although closed-form solutions for $\lambda$ cannot be obtained, we can characterize it explicitly and solve the model numerically. Glosten [1987] speculates that "Since statistical properties of transaction prices are typically a function of both the spread and the composition of the spread, there is no obvious candidate for a simple spread-estimation procedure based on the moments of transactions returns...Furthermore, the results suggest than any attempt to estimate the spread from transaction prices should estimate two components." We agree with his sentiment that it is important to capture the two components, and find that the solution takes an estimable form.

A solution to the more general problem is not more difficult, but to ease notation, we restrict attention to the case where $\gamma=1$. Let $I_{t}=1 * \operatorname{sgn}\left[\omega_{t}\right]$. Dropping time subscripts,

Lemma 2 The demand function for an informed agent is:

$$
\begin{aligned}
& x_{i}(\delta+\epsilon)=\operatorname{MAX}\left\{\left[\frac{v(\delta+\epsilon)}{(v+\phi)}-c_{1} I\right] \frac{1}{2 \lambda}, 0\right\} \text { if } \delta+\epsilon>0 \text { and } \\
& x_{i}(\delta+\epsilon)=\operatorname{MIN}\left\{\left[\frac{v(\delta+\epsilon)}{(v+\phi)}-c_{1} I\right] \frac{1}{2 \lambda}, 0\right\} \text { if } \delta+\epsilon \leq 0 .
\end{aligned}
$$

Proof: See appendix 2.

To solve the equilibrium problem we break it down into three steps:

1. Solve for the critical signal $(\delta+\epsilon)^{*}$ below which no informed trader trades.

2. From the zero profit condition for the market maker, we solve for the market maker's pricing function, $\lambda$, for an arbitrary entry probability, $\pi$.

3. From the comdition that the ex-ante expected profits of an-informed agent must be $\pi c^{*}$, we solve for the entry probability, $\pi$.

The informed agent's expected profits from trading equal:

$$
E \Pi=E\left[\left(\beta(\delta+\epsilon)-\frac{c_{1} I}{2 \lambda}\right)\left(\delta-\lambda\left(\beta(\delta+\epsilon)-\frac{c_{1} I}{2 \lambda}\right)-c_{1} I\right) \mid \delta+\epsilon\right] .
$$


We first solve for $E\left[\delta^{2} \mid \delta+\epsilon\right]$ and $E[\delta \epsilon \mid \delta+\epsilon]$.

\section{Lemma 3}

$$
E\left[\delta^{2} \mid \delta+\epsilon\right]=\frac{v^{2}(\delta+\epsilon)^{2}}{(v+\phi)^{2}}+\frac{v \phi}{(v+\phi)}, \quad E[\delta \epsilon \mid \delta+\epsilon]=\frac{v \phi(\delta+\epsilon)^{2}}{(v+\phi)^{2}}-\frac{v \phi}{(v+\phi)} .
$$

Proof: See appendix 2.

Substituting the results of lemma 3 and $\beta=\frac{v}{2 \lambda(v+\phi)}$ into (14) yields:

$$
E \Pi=\frac{\beta v(\delta+\epsilon)^{2}}{2(v+\phi)}-c_{1} I \beta(\delta+\epsilon)+\frac{\beta c_{1}^{2}(v+\phi)}{2 v} .
$$

This value must be positive for an informed agent to trade. Note that even absent fixed costs, there remains a critical value below which informed traders will not transact,

$$
\left|(\delta+\epsilon)^{*}\right|=\frac{c_{1}}{2 \beta \lambda}=\frac{c_{1}(v+\phi)}{v} .
$$

When $c_{2}$ is added, to determine the critical signal $(\delta+\epsilon)^{*}$ below which an informed agent does not trade, we must first find the signal $(\delta+\epsilon)^{\prime}$ at which the expected profits from transacting equal $c_{2}$, his deadweight trading cost. At $(\delta+\epsilon)^{\prime}$, there is a discrete jump in the specialist's pricing function (see figure 2). But $(\delta+\epsilon)^{*}$ must be less than $(\delta+\epsilon)^{\prime}$. Otherwise, an informed agent could profit by trading the quantity $\omega^{\prime}$ minus some very small quantity, face no adverse selection tariff, and make positive profits. To find $\omega^{*}$, we must determine the slope of the specialist's pricing function and find where it crosses the horizontal line, $p_{t}=F_{t-1}+c_{1}$, where $c_{1}$ reflects the specialist's per-share cost of doing business. This intersection determines $\omega^{*}$. A consequence is that between $\omega^{*}$ and $\omega^{\prime}$, no equilibrium pricing function exists where both the specialist and informed traders earn zero expected profits. If the pricing function is flat between $\omega^{*}$ and $\omega^{\prime}$ the informed trader profits, and if the function is linear (with slope $\lambda$ ) then the market maker profits. We disregard this issue in the later empirical sections.

Equating expected profits, $E \Pi$, with trading cost, $c_{2}$, yields:

$$
\frac{\beta v\left((\delta+\epsilon)^{\prime}\right)^{2}}{2(v+\phi)}-c_{1} I(\delta+\epsilon)^{\prime}+\frac{\beta c_{1}^{2}(v+\phi)}{2 v}-c_{2}=0 .
$$


If $c_{1}=0$,

$$
\left|(\delta+\epsilon)^{\prime}\right|=\sqrt{\frac{2(v+\phi) c_{2}}{\beta v}}
$$

Otherwise:

$$
\left|(\delta+\epsilon)^{\prime}\right|=\frac{c_{1} I(v+\phi)}{v}+\frac{2(v+\phi) \sqrt{\lambda c_{2}}}{v} .
$$

Equation (4) no longer details the zero expected profit condition for the market maker because the conditional probability the market maker faces an informed trader is altered - an informed agent trades only if the absolute value of his signal exceeds $(\delta+\epsilon)^{\prime}$. For smaller signals it is not profitable for an informed agent to transact. Conditional on the volume exceeding $\omega^{\prime}$, the market maker recognizes that he may be trading with an informed trader. The market maker's zero expected profit condition then requires that expected profits net of transaction costs from trading with uninformed liquidity traders equal his losses from trading with the informed:

$$
\pi \int_{-\infty}^{\infty} \int_{-\delta+(\delta+\epsilon)^{\prime}}^{\infty}[E[\Pi]] f_{\delta}(\delta) f_{\epsilon}(\epsilon) d \epsilon d \delta=\lambda \theta \int_{\omega^{\prime}}^{\infty} z^{2} f_{z}(z) d z
$$

where $f_{\delta}(\delta), f_{\epsilon}(\epsilon)$, and $f_{z}(z)$ are the normal probability density functions for $\delta, \epsilon$, and $z$ respectively. Solving implicitly for $\lambda$, we obtain:

$$
\lambda=\sqrt{\frac{\pi}{\eta} \cdot \frac{1}{4(v+\phi)^{2}} \frac{\int_{-\infty}^{\infty} \int_{-\delta+(\delta+\epsilon)^{\prime}}^{\infty}\left[v^{2}(\delta+\epsilon)^{2}-2 c_{1} I(v+\phi)(\delta+\epsilon)+c_{1}^{2}(v+\phi)^{2}\right] f_{\delta}(\delta) f_{\epsilon}(\epsilon) d \epsilon d \delta}{\int_{B(\delta+\epsilon)^{\prime}}^{\infty} z^{2} f_{z}(z) d z} .}
$$

The right-hand side of (16) is continuously decreasing in $\lambda$, approaching infinity as $\lambda$ goes to zero and zero as $\lambda$ approaches infinity. Hence for a given $\pi$, there is a unique solution for $\lambda$. Observe that only the ratio $\frac{\pi}{\eta}$ enters so that once again $\lambda$ is invariant to fluctuations in $\eta$, although now, $\lambda$ is a complicated function of $\sigma$, the variance of uninformed trade.

To solve for the equilibrium entry probability for the informed, $\pi$, we equate expected revenues from being informed with expected costs of becoming informed (including the possibility of trading):

$\frac{1}{4(v+\phi)^{2}} \int_{-\infty}^{\infty} \int_{-\vartheta+(\delta+\epsilon)^{\prime}}^{\infty} \frac{1}{\lambda(\pi)}\left[v^{2}(\delta+\epsilon)^{2}-2 c_{1} I(v+\phi)(\delta+\epsilon)+c_{1}^{2}(v+\phi)^{2}\right] f_{\delta}(\delta) f_{\epsilon}(\epsilon) d \epsilon d \delta=c^{*}(\lambda(\pi))$.

Here we write $\lambda$ explicitly as a function of $\pi$. Observe that both sides of the equation are continuous and that the left-hand side is monotone decreasing approaching infinity as $\pi$ goes 
to zero and zero as $\pi$ approaches 1 . The right-hand side is monotone decreasing, approaching $c+c_{2}$ as $\pi$ goes to zero, and approaching $c$ as $\pi$ approaches 1 . Hence a solution exists, and one can show that the equilibrium sampling probability is unique.

One can integrate and explicitly write equations (16) and (17) as functions of normal distributions. For instance, if $\delta, \epsilon$ and $z$ are each standard normal random variables, and $c_{1}$ is set to zero, these equations are shown in appendix 3 to reduce to

$$
\begin{gathered}
\lambda=\frac{\sqrt{\frac{2 c_{2} \lambda}{p i}} e^{-2 c_{2} \lambda}+1-\Phi\left(2 \sqrt{c_{2} \lambda}\right)}{4\left(c+2 c_{2}\left(1-\Phi\left(2 \sqrt{c_{2} \lambda}\right)\right)\right)} \\
(\delta+\epsilon)^{\prime}=\sqrt{8 c_{2} \lambda} \\
\frac{\pi}{\eta}=\frac{2 \lambda\left(1-\Phi\left(c_{2} / 2 \lambda\right)+\sqrt{\frac{c_{2}}{4 \lambda p i}} e^{\frac{-c_{2}}{4 \lambda}}\right)}{c+2 c_{2}\left(1-\Phi\left(2 \sqrt{c_{2} \lambda}\right)\right)},
\end{gathered}
$$

where we write "pi" to distinguish the number from the sampling probability. Note that $\lambda$ can be solved for directly (numerically) and then resubstituted to obtain $(\delta+\epsilon)^{\prime}$, and $\frac{\pi}{\eta}$. In figures $3-6$, the relationship between transaction costs and the endogenous variables are illustrated. Observe how quickly the probability that a potentially-informed agent actually seeks to acquire inside information falls as transaction costs rise. For example, if $c=.5$, and brokerage and transaction fees, $c_{2}$, are even one tenth the cost of information acquisition, $c$, the probability of acquiring inside information falls by $15 \%$, if total expected costs are held constant. For $c=1$, the reduction is even greater $-20 \%$. In response to the decreased likelihood of trading with an insider, the market maker pares the adverse selection component, $\lambda$, of his pricing function by $8 \%$. That is, small transaction costs can have significant effects on the market maker's pricing function. Note also how the minimum trade size such that an informed trader is willing to trade increases with brokerage fees. The informed trader requires an ever more promising signal for it to be profitable for him to transact as these fees increase, Consequently, there are more signals for which the informed trader will walk away from the_market_maker's_desk. As brokerage fees rise, the probability an informed agent trades falls accordingly.

It is possible to further characterize the equilibrium solution when $c_{1}=0$. Define the locus of combinations of $c$ and $c_{2}$ which yield the same equilibrium expected cost, $c^{*}: c^{*} \equiv$ $c+2\left[1-\Phi(\delta+\epsilon)^{*}\right] c_{2}$. Then, writing the equilibrium $\lambda$ as a function of the fraction of costs 
which are due to information acquisition, $\frac{c}{c^{*}}, \lambda\left(\frac{c}{c^{*}}\right)$ must be increasing in its argument. For suppose that it were constant. Then for any given signal the informed would demand the same quantity for all $c$, conditional on actually trading. But then the informed agent's (positive) expected profits in those trading states are the same for different sampling costs, $c$. However, the greater is $c$ then the lower is $c_{2}$, so there are more signals at which the informed profitably trade. Since expected costs are equal to $c^{*}$ in each scenario, it must be that net expected profits are greater the larger the fraction $c$ represents of expected costs. But net expected profits must be zero independent of the composition of costs, a contradiction. Consequently, as the costs of becoming informed consume a smaller proportion of $c^{*}$, the adverse selection component of the bid-ask spread falls, and the trade volume below which no adverse selection component to the bid-ask spread exists rises. A corollary is that, in order for the market maker to earn zero expected profits, the equilibrium probability that an agent acquires information must fall as $c$ comprises a smaller fraction of $c^{*}$. These observations are illustrated in figures 7 and 8 where the relationship between $\frac{c}{c^{*}}$ and the endogenous variables are detailed for expected total trading costs for the informed of $c^{*}=.5$.

Observe too that at least some liquidity traders benefit from larger transaction costs - they may actually be helped by a tax on transactions. If transaction costs increase marginally, that increase may be sufficient that it ceases to be in the interest of informed traders to trade the same quantity as some liquidity trader. The liquidity trader incurs a marginal increase in costs due to the transaction cost, but receives a lump sum benefit because the adverse selection component to price no longer exists. Similarly, because $\lambda$ falls as transaction costs rise, liquidity traders who trade sufficiently large quantities also benefit. In contrast, liquidity traders who trade very small quantities lose as transaction costs increase because the degree of adverse selection the market maker faces for such transaction volumes is similarly small. See figure 9 . Ex ante, however, liquidity traders do not gain from an increase in transaction costs.

If $c_{1}>0$, there is negative serial correlation in the price series which provides additional information about the sign of $\omega$. The entire trading history is now relevant because the fixed transaction costs imply prices no longer follow a martingale. The estimate of $c_{1}$ here (and in Glosten and Harris [1989]) provides a lower bound on the cost of trading since the total trading 
cost presumably includes brokerage fees. A more relevant statistic may be the estimate of $\omega^{*}$, the smallest trade insiders are willing to make. This value is unaffected by the division of transaction costs into observed (price) and unobserved (brokerage fee) components. From $\omega^{*}$, the estimate of brokerage fees can then be unraveled.

\section{Estimation procedure}

We assume that all trades are processed sequentially as they appear on the tape, and an informational innovation occurs each period.

Estimation without transaction costs when the sign of $\omega$ is unobservable.

Let there be $n$ transactions and let prices, volumes, and indicator functions be indexed by time, not by transaction. Estimation is accomplished by taking price differences from successive trades. Suppose adjacent transactions occur at times $s-t$ and $s$. Recall:

$$
p_{s}=F_{s-1}+\lambda_{s} \omega_{s} ; p_{s-t}=F_{s-t-1}+\lambda_{s-t} \omega_{s-t} .
$$

We can rewrite $p_{s}$ as:

$$
p_{s}=F_{s-t-1}+\sum_{\tau=s-t}^{s-1} \delta_{\tau}+\lambda_{s} \omega_{s}
$$

Then,

$$
\Delta p_{s}=p_{s}-p_{s-t}=\left[\delta_{s-t}-\lambda_{s-t} \omega_{s-t}\right]+\sum_{\tau=s-t+1}^{s-1} \delta_{\tau}+\lambda_{s} \omega_{s}
$$

$\left[\delta_{s-t}-\lambda_{s-t} \omega_{s-t}\right]$ is the projection error due to the information released about $\delta_{s-t}$ immediately following the trade at $s-t . \sum_{\tau=s-t}^{s-1} \delta_{\tau}$ is the balance of the information released between the two trades. Thus, (18) can be writen as:

$$
\Delta p_{s}=\lambda_{\text {si is }}+\epsilon_{s}
$$

Although quantities traded by both informed and uninformed traders are normal random variables with zero mean and variances $\beta^{2}(v+\phi)$ and $\sigma$, and $\delta$ is itself normally distributed, $e_{s}$ and $\omega_{s}$ are mixtures of normal distributions. The mixtures are due not only to the unobservability of the sign of $\omega$ (as in Glosten and Harris [1989]), but also because informed and uninformed agents (who trade quantities drawn from different normal distributions) cannot be distinguished from each other. These additional mixtures identify the structural parameters of the model. Our 
estimation procedure, which maximizes the unconditional likelihood of jointly observing the sequence of price changes $\{\Delta p\}=\left\{\Delta p_{1}, \ldots, \Delta p_{n}\right\}$, and the volume sequence $\{|\omega|\}=\left\{\left|\omega_{1}\right|, \ldots,\left|\omega_{n}\right|\right\}$ is given in appendices 3 and 5 . Were $\omega_{s}$ observable or the (noisy) Lee-Ready [1991] procedure used to identify the sign of the trade from the quote data, ordinary least squares would provide consistent but inefficient parameter estimates. The inefficiency is due to the unobservability of the identities of the traders (informed or uninformed).

Simply assuming that price increases (decreases) indicate buy (sell) orders clearly biases the results upward. In Table 4 we compare the $\lambda$ obtained using the correct procedure with estimates of $\lambda$ obtained using OLS, assuming that price increases (decreases) indicate buy (sell) orders, and lack of price movement indicates that the sign of the bid-ask indicator is the same as that of the previous transaction.

\section{The data}

The Fitch database of all transactions for all stocks on the NYSE between January 2, 1980 and January 6, 1981 is used to test the model. We remove securities which experience stock splits or receive distributions other than normal cash dividends. Regular dividends are paid overnight, and their effects are felt only at open. For the remaining stocks, we examine the entire price series, forming price differences between adjacent trades. Since prices on open and close may be determined by call auctions or de facto call auctions, the first trade of the day, the last trade of the day, and all other trades processed at these times are eliminated. All price differences which contain these trades are also removed. We also remove trades around trading halts, trades which appear out of order on the tape, trades which are marked with a correction code or certain condition codes, trades at negative prices (known errors), and trades with price changes of more than $20 \%$. For frequently traded securities, we restrict attention to the first 5000 remaining price differences. Finally; when comparing parameters across different time periods, we eliminate price changes which cross trourly-boundaries.

\section{Testable implications}

In the absence of transaction costs, the theory provides non-linear restrictions which identify the structural parameters of the specialist's pricing function: $v$, the amount of inside informa- 
tion, $\phi$, the noise in the signal, $c$, the cost of information, and $\sigma$, the variance of uninformed trade. These structural parameters in turn provide information about other quantities of interest: $\lambda$, the slope of the specialist's pricing function; $\theta$, the probability that the specialist faces an informed trader; and the average quantities traded by both informed and uninformed agents. Estimation of the structural parameters allows us to distinguish for example whether a high $\lambda$ is due to more private information, $v$, or a less noisy signal, $\phi^{-1}$.

We estimate the pricing function over different intraday intervals to see if there is systematic variation in it over the course of the day. We then test the linear pricing rule against a quadratic alternative. Finally, we test the restrictions which identify the structural parameters against an alternative which does not impose the restrictions. There are six reduced form parameters, four structural parameters, and two nonlinear restrictions which map the reduced form parameters to the structural parameters.

When transaction costs are integrated into the model, identification of some structural parameters becomes infeasible. However, we can still estimate the probability that a particular trader is informed as well as the average quantities traded by informed and uninformed traders. In addition, both a per-share transaction cost, $c_{1}$, and a quantity cutoff, $\omega^{*}$, below which there is no adverse selection are estimated. Unlike the linear pricing rule estimated by Glosten and Harris [1989], the resulting pricing function is kinked. We test the linear pricing rule against the kinked alternative.

\section{Results}

\subsection{Estimation of $\lambda$ when the sign of $w$ is unobservable}

We first estimate the slope of the specialist's pricing function, $\lambda$ when the sign of $\omega$ is not observable. Since here, we are just comparing these $\lambda$ with those obtained using the OLS procedure detailed in section 4, we simplify the estimation problem by assuming that $\operatorname{var}\left(e_{i}\right)$ is constant. While our theory implies that $\operatorname{var}\left(e_{i}\right)$ is ceteris paribus linear in the time between trades, we justify this simplifying assumption because, when we allowed $\operatorname{var}\left(e_{i}\right)$ to be linear in the time between transactions, (i.e. $\operatorname{var}\left(\epsilon_{i}\right)=k_{0}+k_{1} t$, where $t$ is the time between trades), estimates of $k_{1}$ were found to be insignificantly different from zero, as in Glosten and 
Harris [1989]. ${ }^{6}$ This may be because informational innovations are infrequent so that they are correlated with informed trade.

In general, $\operatorname{var}\left(e_{i}\right)$ is a function of the identity of the trader (informed or uninformed) at both time $s$ and time $s-t$. This more complicated relationship identifies the structural parameters of the model. Those results are presented in section 7.2.

Parameter estimates are presented in Table 1. $\lambda$ is the estimate of the slope of the specialist's pricing function in dollar price change per 1000 share trade, taking into account the unobservability of the sign of $\omega$. Therefore, if the price rises, $\operatorname{pr}(\omega>0 \mid \Delta p>0)$ will not be one. It is, however, increasing in the magnitude of the price movement. Except for ABC, there appears to be a significantly positive adverse selection component to the bid-ask spread. ${ }^{7} \lambda$ appears to decrease with trading volume. Although the model places no restrictions on the relationship between firm size and adverse selection. this result would be consistent with Foster and Viswanathan's [1990] observation that less private information is available about large, frequently traded, securities.

When the sample is divided into six trading hours, (see Table 2), we reject the hypothesis that $\lambda$ and $\operatorname{var}(e)$ are constant across the trading day $\left(\chi^{2}(10)=24.13\right) . \lambda$ is high during hours 1,2 , and 6 , but it is also high during hour 4 . The lack of systematic correlation between $\lambda$ and price variance is even more pronounced for $A A A$. Here, we cannot reject the null hypothesis that $\lambda$ is constant across the day $\left(x^{2}(10)=5.75\right)$.

Theory predicts that the adverse selection component is smaller at open and close if there is discretionary liquidity trade (Bernhardt and Hughson [1992a]). Unfortunately, the specialist pools orders on open and close, and we do not have a formal procedure for extracting net order flow from price and volume data. We can still informally test the hypothesis that the adverse selection component is smaller on open and close by estimating the model during the first and last 15 minutes of the day assuming no pooling and including opening and closing

\footnotetext{
'Hausman, Lo, and MacKinlay' [1992] find that when they' account for discreteness, the time between trades is indeed a determinant of the variance of public information release, which is consistent with our model.

${ }^{7}$ When $\lambda$ approaches zero, the algorithm GQOPT ceases to converge - there are no longer four independent first order conditions at the limit.
} 
trades. However, we find that $\lambda$ is higher there than at any other time. This suggests that liquidity traders do not time their trades: Discretionary trade is not an important component of order flow.

\subsection{Structural parameter estimation}

Here we estimate the structural parameters for the model in the absence of transaction costs (see appendix 3). Due to the shape of the likelihood function, gradient methods of estimation did not converge. Consequently, the maxima were found using a grid search. Standard errors are also found numerically.

Estimates are provided for Alcoa Aluminum in Table 5. The structural parameters are all found to be statistically significant. It is comforting to find that the estimates of the slope parameter, $\lambda$, are similar in magnitude to those in Table 4.

Previous literature attributes changes in $\lambda$ to changes in the "amount" of information about the stock. Our estimation procedure distinguishes between the "amount" of information and its "quality". We find that $v$, the variance of inside information, is nearly constant throughout the day. In Table 5, we see small changes in $v$ accompanied by large changes in $\lambda$ (see hours 2 and 3 ). However, $\phi$, the noise in the signal is much higher in the middle of the day. Thus, changes in $\lambda$ appear to be almost completely determined by changes in $\phi$.

For Alcoa (AA), a 1000 share purchase (approximately $\$ 60,000$ ) results in a tariff of $\$ 4.19$ due to adverse selection (see Table 5). Even for a 10.000 share trade, where the tariff rises to $\$ 419$, it is still economically tiny, about .1\% of the investment. For some securities, the adverse selection tariff is greater, up to $\$ 2000$ for a 10.000 share (see Table 7 ), which is on the order of $1 \%$ of the investment. Since these tariffs are small relative to the size of the price grid, it appears to be important to incorporate the discreteness of the price grid into the analysis.

Over the day, the average informational innovation exceeds an eighth, $\$ .1353$, and the signal to noise ratio is about .5. Not surprisingly, insiders trade much larger quantities than uninformed traders, averaging 7002 and 458 shares. respectively. See figure 10 for the distribution of traded quantities for the 5000 Alcoa orders. While the estimated probability a given trader is informed is $.43 \%$. it is close to zero for small orders $(.03 \%$ for hundred share orders, $.3 \%$ for 
1000 share orders), it rises precipitously between 1000 and 2000 shares (see figure 11). Except for orders between 1000 and 2000 shares, it is relatively easy to distinguish informed trade from uninformed trade. The very low estimate of informed trade for small orders suggests that fixed transaction costs discourage them from trading such quantities.

Still, the small fraction of informed traders seems implausible. Examination of the specialist's zero profit condition (equation (4)) shows that the expected profits of the informed on a 10000 share order are extremely high - almost $\$ 100,000$, about $\$ 10$ per share. When the nonlinear restrictions are relaxed (see Table 6), the probability of an informed trader rises to over $9 \%$, and the expected profits of the informed drop to a more reasonable $\$ 4200$.

In Table 6, the model is tested against two alternatives. First, the two nonlinear restrictions implied by the model are relaxed: we just estimate the reduced form parameters of the model. This exercise is, in some sense, equivalent to that in Gilosten and Harris, who estimate an econometric specification rather than a structural model. When the mapping from the reduced form to the structural parameters is removed, some structural parameters are now unidentifiable, but the fit improves dramatically. We strongly reject the nonlinear restrictions imposed by the model $\left(\chi^{2}(2)=612\right)$. Symptoms of the bad fit include the low probability of informed trade and the unreasonably large profits of the insiders when they trade large quantities. While the slope of the pricing function and the quantities traded by market participants are unaltered, the probably of informed trade increases to over $9 \%$. Second, the model is tested against a nonlinear rule. The immediate concern is whether the specialist is also inferring whether large trades are due to informed agents. As a simple diagnostic, we test the model against a quadratic pricing rule. Surprisingly the quadratic coefficient, $d$, is neither economically nor statistically significant. We conjecture that $d$ may be negative only because transaction costs are excluded from the model here. If the price increases by $C$ ! whenever shares are bought, regardless of the size of the order, a first order quadratic approximation without transaction costs would appear to be concave.

Table 7 provides parameter estimates for other securities. Note that for smaller stocks (not $\left.A B C^{\prime}\right)$, both informed and uninformed agents tend to trade smaller quantities, and $\lambda$ appears to be greater. Note also that $\lambda_{A B C}$ is quite low: the adverse selection tariff is $\$ 1.90$ for a thousand 
share order. This is consistent with the (lack of an) estimate for $\lambda_{A B C}$ in Table 1.

\subsection{The Effect of Transaction Costs.}

When transaction costs are included, structural parameter estimation becomes infeasible. The structure of the model looks like the unrestricted alternative from Table 6 with the addition of transaction costs. When investors face a fixed cost to execute their trades, below a critical value $(\delta+\epsilon)^{*}$, there is no adverse selection problem. Figure 3 shows that ignoring the consequences of $c_{2}$ biases estimates of $\lambda$ downward. The additional per-share cost, $c_{1}$, paid to the specialist, introduces serial correlation, so the past transaction history is relevant. The estimation is complicated by the need to integrate over all possible transaction paths (see appendix 5 ). The procedure is similar to that used to integrate over all possible series of informed/uninformed indicators. Because the overnight non-trading period is long, and there are presumably many informational innovations, we assume that the probability that the opening trade is a buy is

$\frac{1}{2}$. This significantly reduces the relevant number of potential transaction paths because the likelihood of $\Delta p_{s}$ depends only on trades which take place in the same day. Estimation of the critical level of trade $\omega^{*}$ below which no adverse selection problem exists involves including $\omega$ as an explanatory variable above the critical level, and omitting it otherwise [Judge 1985 pp 803-806].

We estimate $\lambda$, the critical cutoff, and the variances of both informed and uninformed trade. Results for Alcoa Aluminum (AA) are given in Table 8. They indicate that the introduction of transaction costs to the econometric model reduces $\lambda$ to .0025 , as predicted. Transaction costs are estimated to be about $\$ .032$ per share and the critical cutoff is estimated to be 1300 shares $\left(\chi^{2}(1)=248.32(>.99)\right)$, which means that informed traders place few orders for Alcoa of less than $\$ 65,000$. As one would hope, the estimated average trade sizes of both the informed and uninformed are unaffected by the introduction of transaction costs. The reason that this estimate is unchanged is that even without transaction costs, the estimated probability that an individual trading a quantity less than 1400 shares is informed is close to nil.

\section{Extensions and comments}

\subsection{Event studies}


The methodology can be used to examine whether increased price variance around major events such as earnings, dividend, and merger announcements can be explained by an increase in the amount of inside information near the announcement dates.

\subsection{Cross-sectional tests}

Informational events may affect more than a single security. The analysis presented here can be extended to the case where there is contemporaneous correlation in informational innovations across securities, i.e. to where the informational innovations contain both a common market-wide component and a security-specific idiosyncratic component. However, there is the additional problem of non-synchronous trading across securities: There is only partial overlap of price change intervals for different securities. Fortunately, the model implies the correlation between the regression errors of two securities is linear in the time overlap, and it is not difficult to apply a modified "seemingly unrelated" regressions technique to estimate the model. Given the amount of cross-sectional correlation in security returns, it is not unreasonable to expect an efficiency gain from this approach. Details are given in Bernhardt and Hughson [1992c].

\subsection{Discreteness in prices and time between trades.}

Harris [1986], and Cilosten and Harris [1989] recognize that transaction prices come from a, discrete price grid with increments of an eighth which is about fifteen times the estimated pershare adverse selection component for a 1000 share order for Alcoa. They assume that the "true value" is a continuous variable and that agents round the price to the nearest eighth. They note that rounding is fundamentally ad-hoc. Unfortunately, the magnitude of the error introduced by discreteness seems enormous relative to the information effects. Our results suggest that not only does discreteness play an important role in determining the price series, but it may also play an important role in determining the strategies of the potentially-informed agents, and hence, the specialist. These issues are examined in Bernhardt and Hughson [1992b].

\section{Conclusion}

We develop a model of insider trading on the NYSE which is consistent with many of the stylized facts found in the empirical literature. When markets are thin, we show that the specialist's pricing function is unaffected by the expected trade volume. This permits estimation 
of the structural model. Since transactions are processed independently, we can incorporate transaction cost components into the model. Then the adverse selection component to the specialist's pricing function vanishes for small transaction sizes, and the price series is negatively serially correlated. The theory imposes testable restrictions on transaction-by-transaction data. These econometric tests are performed using maximum likelihood estimation which takes into account the unobservability of the side of the trade taken by the market maker as well as the identity (informed or uninformed) of the trader. The theory provides additional non-linear restrictions which identify of the structural parameters in the economy: the amount of private information, the noise in the signal, the cost of information, and the variance of uninformed trade. We find that there is a substantial amount of private information, but the quality of an insider's signal is so bad that the estimated price impact of information is small. This may be due in part to the structure of the NYSE itself, in particular, the existence of limit orders and price continuity requirements for the specialist. This may cause the price impact of information to be spread over several trades. This may also minimize the apparent price impact of information of a single trade.

When fixed and variable transaction costs are introduced, estimation of the structural parameters is infeasible. However, a transaction cost component and a critical value below which no adverse selection exists emerges can be estimated. The critical cutoff is found to be large - insiders do not trade small quantities. We strongly reject the linear pricing rule when it is tested against the kinked alternative. This suggests that transaction costs are significant in limiting the ability of informed traders to divide their trades. 
Table 1: Parameter Estimates**

\begin{tabular}{|c|c|c|c|c|c|c|c|}
\hline SYM & FIRM & $\begin{array}{r}\text { TOTAL } \\
\text { TRADES }\end{array}$ & $\begin{array}{c}\text { TRADES } \\
\text { INCL. }\end{array}$ & $\lambda$ & $\operatorname{var}[e]$ & $\mu_{0}$ & $\mu_{1}$ \\
\hline $\mathrm{AA}$ & Alcoa Aluminum & 13002 & 5000 & $\begin{array}{r}.00420 \\
(.00074)\end{array}$ & $\begin{array}{r}.01790 \\
(.00046)\end{array}$ & $\begin{array}{r}.00131 \\
(.00219)\end{array}$ & $\begin{array}{r}-.00038 \\
(.00032)\end{array}$ \\
\hline $\mathrm{AAA}$ & Amer. $\mathrm{S} \& \mathrm{~L}$ of $\mathrm{FL}$ & 2153 & 847 & $\begin{array}{r}.05113 \\
(.01303)\end{array}$ & $\begin{array}{r}.02122 \\
(.00100)\end{array}$ & $\begin{array}{r}.00089 \\
(.00651)\end{array}$ & $\begin{array}{r}-.00061 \\
(.00041)\end{array}$ \\
\hline $\mathrm{AAE}$ & Amerace Corp. & 1903 & 709 & $\begin{array}{r}.03138 \\
(.00987)\end{array}$ & $\begin{array}{r}.02232 \\
(.00097)\end{array}$ & $\begin{array}{r}.00790 \\
(.00769)\end{array}$ & $\begin{array}{r}-.00011 \\
(.00055)\end{array}$ \\
\hline $\mathrm{ABC}$ & Amer. Broadcasting Co. & 10434 & 5000 & $0^{*}$ & & & \\
\hline $\mathrm{ABF}$ & Airborne Flight Corp. & 2323 & 945 & $\begin{array}{r}.01117 \\
(.00224)\end{array}$ & $\begin{array}{r}.02471 \\
(.00157)\end{array}$ & $\begin{array}{r}.00397 \\
(.00670)\end{array}$ & $\begin{array}{r}-.00038 \\
(.00045)\end{array}$ \\
\hline $\mathrm{ABT}$ & Abbot Corp. & 10057 & 5000 & $\begin{array}{r}.00580 \\
(.00090)\end{array}$ & $\begin{array}{r}.01521 \\
(.00033)\end{array}$ & $\begin{array}{r}.00379 \\
(.00230)\end{array}$ & $\begin{array}{r}-.00037 \\
(.00026)\end{array}$ \\
\hline $\mathrm{ABY}$ & Albany International & 3289 & 1788 & $\begin{array}{r}.01498 \\
(.00838)\end{array}$ & $\begin{array}{r}.02838 \\
(.00085)\end{array}$ & $\begin{array}{r}.00103 \\
(.00494)\end{array}$ & $\begin{array}{r}.00062 \\
(.00039)\end{array}$ \\
\hline ABZ & Arkansas Best Corp. & 1438 & 365 & $\begin{array}{r}.03190 \\
(.00840)\end{array}$ & $\begin{array}{r}.00962 \\
(.00066)\end{array}$ & $\begin{array}{r}-.00176 \\
(.00763)\end{array}$ & $\begin{array}{r}.00051 \\
(.00041)\end{array}$ \\
\hline $\mathrm{ACA}$ & Arcata Corp. & 3150 & 1519 & $\begin{array}{r}.00259 \\
(.00205)\end{array}$ & $\begin{array}{r}.02092 \\
(.00074)\end{array}$ & $\begin{array}{r}.00959 \\
(.00050)\end{array}$ & $\begin{array}{r}-.00056 \\
(.00033)\end{array}$ \\
\hline
\end{tabular}

*: Estimation procedure did not converge - all parameters are not separately identified when $\lambda$ is in the neighborhood of zero.

Standard errors are given in parentheses directly below the point estimates.

Appendix 1. tables 
Table 2: Hourly Estimates for Alcoa Aluminum (AA) and Amer. S \& L of FL (AAA)

\begin{tabular}{|c|c|c|c|c|c|}
\hline HR & TRADES & $\lambda$ & $\operatorname{var}[e]$ & $\begin{array}{r}\mu_{0} \\
\text { trend } \\
\end{array}$ & $\begin{array}{r}\mu_{1} \\
\text { components } \\
\end{array}$ \\
\hline $\mathrm{AA}$ & & & & $\begin{array}{r}.00168 \\
(.00219)\end{array}$ & $\begin{array}{r}-.00033 \\
(.00006)\end{array}$ \\
\hline 1 & 1068 & $\begin{array}{r}.00502 \\
(.00199)\end{array}$ & $\begin{array}{r}.01834 \\
(.00084)\end{array}$ & & \\
\hline 2 & 1035 & $\begin{array}{r}.00661 \\
(.00238)\end{array}$ & $\begin{array}{r}.01690 \\
(.00092)\end{array}$ & & \\
\hline 3 & 703 & $\begin{array}{r}.00264 \\
(.00060)\end{array}$ & $\begin{array}{r}.01687 \\
(.00116)\end{array}$ & & \\
\hline 4 & 575 & $\begin{array}{r}.00474 \\
(.00194)\end{array}$ & $\begin{array}{r}.01485 \\
(.00098)\end{array}$ & & \\
\hline 5 & 750 & $\begin{array}{r}.00367 \\
(.00104)\end{array}$ & $\begin{array}{r}.01874 \\
(.00095)\end{array}$ & & \\
\hline 6 & 857 & $\begin{array}{r}.00447 \\
(.00218) \\
\end{array}$ & $\begin{array}{r}.02048 \\
(.00164) \\
\end{array}$ & & \\
\hline $\mathrm{AAA}$ & & & & $\begin{array}{r}.00781 \\
(.00675)\end{array}$ & $\begin{array}{r}-.00057 \\
(.00327)\end{array}$ \\
\hline 1 & 203 & $\begin{array}{r}.05678 \\
(.01193)\end{array}$ & $\begin{array}{r}.02299 \\
(.00204)\end{array}$ & & \\
\hline 2 & 249 & $\begin{array}{r}.02617 \\
(.03658)\end{array}$ & $\begin{array}{r}.02399 \\
(.00192)\end{array}$ & & \\
\hline 3 & 112 & $\begin{array}{r}.08025 \\
(.03130)\end{array}$ & $\begin{array}{r}.01841 \\
(.00274)\end{array}$ & & \\
\hline 4 & 84 & $\begin{array}{r}-.00735 \\
(.27496)\end{array}$ & $\begin{array}{r}.01797 \\
(.00278)\end{array}$ & & \\
\hline 5 & 114 & $\begin{array}{r}.00000 \\
(.00466)\end{array}$ & $\begin{array}{r}.02229 \\
(.00231)\end{array}$ & & \\
\hline 6 & 85 & $\begin{array}{r}.07251 \\
(.02552\end{array}$ & $\begin{array}{r}.01957 \\
(.00327)\end{array}$ & & \\
\hline
\end{tabular}

Standard errors are given in parentheses directly below the point estimates. 
Table 3: Estimates of Price and Volume for Alcoa Aluminum (AA) and Amer. S \& L of FL (AAA)

\begin{tabular}{|r|r|r|r|r|r|}
\hline SYM & HR & VAR(price) & $\begin{array}{r}E\left[\omega^{2}\right]^{*} \\
\text { per } 1000\end{array}$ & $\begin{array}{r}E[|\omega|] \\
\text { thousands }\end{array}$ & $\begin{array}{r}\text { SAMPLE } \\
\text { SIZE }\end{array}$ \\
\hline AA & ALL & 0.01813 & 12.692 & 1.266 & 5000 \\
& 1 & 0.01862 & 10.569 & 1.354 & 1068 \\
& 2 & 0.01724 & 8.281 & 1.182 & 1035 \\
& 3 & 0.01698 & 17.461 & 1.211 & 703 \\
& 4 & 0.01485 & 15.585 & 1.373 & 575 \\
& 5 & 0.01899 & 18.228 & 1.319 & 750 \\
& 6 & 0.02050 & 9.888 & 1.185 & 857 \\
\hline AAA & ALL & 0.02245 & 0.443 & 0.399 & 847 \\
& 1 & 0.02503 & 0.650 & 0.483 & 203 \\
& 2 & 0.02277 & 0.446 & 0.362 & 249 \\
& 3 & 0.01996 & 0.323 & 0.363 & 112 \\
& 4 & 0.01734 & 0.285 & 0.364 & 84 \\
& 5 & 0.02246 & 0.297 & 0.396 & 114 \\
& 6 & 0.02207 & 0.451 & 0.392 & 85 \\
\hline
\end{tabular}

* $E\left[(\operatorname{volume})^{2}\right]$ is a measure of $\operatorname{var}[\omega]$, because the theory implies that $E[\omega]=0$.

Table 4: Comparison of Pricing Functions: OLS vs. Maximum Likelihood (table 1)

\begin{tabular}{|r|r|r|r|r|}
\hline SYM & $\begin{array}{r}\lambda \\
(\text { OLS })\end{array}$ & $\begin{array}{r}\operatorname{var}[e] \\
\text { (OLS) }\end{array}$ & $\begin{array}{r}\lambda \\
\text { table 1 }\end{array}$ & $\begin{array}{r}\operatorname{var}[e] \\
\text { table 1 }\end{array}$ \\
\hline AA & .009 & .017 & .004 & .018 \\
AAA & .113 & .017 & .051 & .021 \\
AAE & .098 & .018 & .031 & .022 \\
ABC & .005 & .010 & $*$ & $*$ \\
ABF & .017 & .023 & .011 & .025 \\
ABT & .013 & .014 & .006 & .015 \\
ABY & .037 & .026 & .015 & .028 \\
ABZ & .065 & .007 & .032 & .010 \\
AC:A & .010 & .020 & .002 & .021 \\
\hline
\end{tabular}

*: Estimation procedure did not converge - all parameters are not separately identified when $\lambda$ is in the neighborhood of zero. See appendix 4 for details. 
Table 5: Hourly Structural Parameter Estimates for Alcoa Aluminum (AA)

\begin{tabular}{|c|c|c|c|c|c|c|c|}
\hline HOUR & $\overline{\mathrm{ALL}}$ & 1 & 2 & 3 & 4 & 5 & 6 \\
\hline TRADES & 5000 & 1068 & 1035 & 703 & 575 & 750 & 857 \\
\hline \multicolumn{8}{|c|}{ STRUCTURAL PARAMETERS } \\
\hline \multirow[t]{3}{*}{$v$} & \multicolumn{7}{|c|}{ variance of inside information } \\
\hline & .01829 & .01888 & .01736 & .01704 & .01536 & .01921 & .02096 \\
\hline & $(.00037)$ & $(.00084)$ & $(.00077)$ & $(.00091)$ & $(.00924)$ & $(.00101)$ & $(.00103)$ \\
\hline \multirow[t]{3}{*}{$\phi$} & \multicolumn{7}{|c|}{ noise in the signal } \\
\hline & .08212 & .07315 & .11480 & .15360 & .05075 & .07211 & .05401 \\
\hline & $(.02404)$ & $(.04194)$ & $(.08388)$ & $(.16174)$ & $(.03239)$ & $(.04988)$ & $(.04988)$ \\
\hline \multirow[t]{3}{*}{$\sigma$} & \multicolumn{7}{|c|}{ variance of uninformed trade } \\
\hline & 20940 & .22395 & 20938 & 20777 & .14253 & 18319 & .23239 \\
\hline & $(.00334)$ & $(.00759)$ & $(.00888)$ & $(.00765)$ & $(.00691)$ & $(.00769)$ & $(.00904)$ \\
\hline \multirow[t]{3}{*}{$c$} & \multicolumn{7}{|c|}{ cost of information $(\$)$} \\
\hline & 20.213 & 18.933 & 13.826 & 17.293 & 21.709 & $\begin{array}{r}27.199 \\
7\end{array}$ & 24.231 \\
\hline & $(2.553)$ & $(4.614)$ & $(4.532)$ & $(8.406)$ & $(5.784)$ & $(7.927)$ & $(5.747)$ \\
\hline \multicolumn{8}{|c|}{ EC!ONOMIC! PARAMETERS } \\
\hline \multirow[t]{6}{*}{$\lambda$} & \multicolumn{7}{|c|}{ slope of specialist's pricing function } \\
\hline & .00412 & .00512 & .00412 & .00246 & .00411 & .003714 & .00604 \\
\hline & \multicolumn{7}{|c|}{ Adverse selection tariff for a 1,000 share order, $\$(\lambda \omega)^{2}$} \\
\hline & 4.12 & 5.12 & 4.12 & 2.46 & 4.11 & 3.71 & 6.04 \\
\hline & \multicolumn{7}{|c|}{ Adverse selection tariff for a 10,000 share order, $\$(\lambda \omega)^{2}$} \\
\hline & 412.00 & 512.00 & 412.00 & 246.00 & 411.00 & 371.00 & 604.00 \\
\hline$\theta$ & \multicolumn{7}{|c|}{ ex-ante probability that a trader is informed } \\
\hline \multirow{5}{*}{$\sqrt{\sigma}$} & .00425 & .00602 & .00621 & .00295 & .00269 & .00250 & .00584 \\
\hline & \multicolumn{7}{|c|}{ average size of an uninformed trade (shares) } \\
\hline & 458 & 473 & 458 & 456 & 378 & 428 & 485 \\
\hline & \multicolumn{7}{|c|}{ average size of an informed trade (shares) } \\
\hline & 7002 & 6083 & 5790 & 8:384 & 7267 & 8558 & 6332 \\
\hline$\sqrt{v}$ & \multicolumn{7}{|c|}{ a.verage size of price shock $\$$} \\
\hline \multirow{3}{*}{$\sqrt{\phi}$} & .1353 & .1374 & .1318 & .1305 & .1240 & .1386 & .1448 \\
\hline & \multicolumn{7}{|c|}{ average amount of noise $\$$} \\
\hline & .2866 & .2705 & .3388 & .3919 & .2253 & .2685 & .2324 \\
\hline
\end{tabular}

Standard errors are given in parentheses directly below the point estimates.

Test of whether hourly parameter estimates significantly differ from each other: $\left(\chi^{2}(20)=\right.$ $152.002(>.995))$ 
Table 6: Test of Nonlinear Restrictions Implied by the Model - Test of Linearity of the Pricing Function - for Alcoa Aluminum

\begin{tabular}{|c|c|c|c|}
\hline & $\begin{array}{r}\text { THE } \\
\text { MODEL }\end{array}$ & $\begin{array}{r}\text { UNRESTRICTED } \\
\text { ALTERNATIVE }\end{array}$ & $\begin{array}{r}\text { NONLINEAR } \\
\text { RULE }\end{array}$ \\
\hline \multicolumn{4}{|c|}{ STRUCTURAL PARAMETERS } \\
\hline$\vec{v}$ & \multicolumn{3}{|c|}{ variance of inside information } \\
\hline & .01829 & $*$ & .01836 \\
\hline & $(.00037)$ & & $(.00038)$ \\
\hline \multirow[t]{3}{*}{$\phi$} & \multicolumn{3}{|c|}{ noise in the signal } \\
\hline & .08212 & * & .06900 \\
\hline & $(.02404)$ & * & $(.01472)$ \\
\hline \multirow[t]{3}{*}{$\sigma$} & \multicolumn{3}{|c|}{ variance of uninformed trade } \\
\hline & .20940 & .20843 & .20948 \\
\hline & $(.00334)$ & $(.00448)$ & $(.00334)$ \\
\hline \multirow[t]{3}{*}{$c$} & cost of inf & rmation $(\$)$ & \\
\hline & 20.213 & * & 21.728 \\
\hline & & & \\
\hline \multicolumn{4}{|c|}{ ECONOMIC PARAMETERS } \\
\hline \multirow[t]{7}{*}{$\bar{\lambda}$} & \multicolumn{3}{|c|}{ slope of specialist's pricing function } \\
\hline & .00412 & .00419 & .00444 \\
\hline & $*$ & $(.00070)$ & * \\
\hline & \multicolumn{3}{|c|}{ Adverse selection tariff for a 1,000 share order, $\$(\lambda \omega)^{2}$} \\
\hline & 4.12 & 4.19 & 4.44 \\
\hline & \multicolumn{3}{|c|}{ Adverse selection tariff for a 10,000 share order, $\$(\lambda \omega)^{2}$} \\
\hline & 412.00 & 419.00 & 444.00 \\
\hline \multirow[t]{3}{*}{$\mathrm{d}$} & \multicolumn{3}{|c|}{ quadratic pricing function term } \\
\hline & & * & -.0000140 \\
\hline & * & $*$ & $(.0000141)$ \\
\hline \multirow[t]{3}{*}{$\theta$} & \multicolumn{3}{|c|}{ ex-ante probability that a trader is informed } \\
\hline & .00425 & .09048 & .00426 \\
\hline & * & $(.00767)$ & * \\
\hline \multirow[t]{5}{*}{$\sqrt{\sigma}$} & \multicolumn{3}{|c|}{ average size of an uninformed trade (shares) } \\
\hline & 458 & 457 & 458 \\
\hline & \multicolumn{3}{|c|}{ average size of an informed trade (shares) } \\
\hline & 7002 & 8049 & 6995 \\
\hline & * & $(369.395)$ & $*$ \\
\hline \multirow[t]{2}{*}{$\sqrt{v}$} & \multicolumn{3}{|c|}{ average size of price shock $\$$} \\
\hline & .1353 & $* 1$ & $.135 \dot{5}$ \\
\hline \multirow[t]{2}{*}{$\sqrt{\phi}$} & \multicolumn{3}{|c|}{ average amount of noise $\$$} \\
\hline & .2866 & * & .2627 \\
\hline
\end{tabular}

*: The nonlinear restrictions identify some, but not all structural parameters.

Standard errors are given in parentheses directly below the point estimates.

Test against unrestricted alternative: $\left(\chi^{2}(2)=612.059 !(>.999)\right)$. 
Table 7: Structural Parameter Estimates other NYSE Securities

\begin{tabular}{|c|c|c|c|c|c|}
\hline SYMBOL & AAA & AAE & $\mathrm{ABC}$ & $\mathrm{ABF}$ & $\overline{\mathrm{ABT}}$ \\
\hline & 1380 & 1187 & 2000 & 945 & 2000 \\
\hline \multicolumn{6}{|c|}{ STRUCTURAL PARAMETERS } \\
\hline \multirow[t]{3}{*}{$v$} & \multicolumn{5}{|c|}{ variance of inside information } \\
\hline & .02392 & .02380 & .01150 & .02571 & .01563 \\
\hline & $(.00092)$ & $(.00092)$ & $(.00037)$ & $(.00118)$ & $(.00048)$ \\
\hline \multirow[t]{3}{*}{$\phi$} & \multicolumn{5}{|c|}{ noise in the signal } \\
\hline & .05379 & .81912 & $.0545 i$ & .04121 & .16636 \\
\hline & $(.02044)$ & $(.57903)$ & $(.01604)$ & $(.02035)$ & $(.14401)$ \\
\hline \multirow[t]{3}{*}{$\sigma$} & \multicolumn{5}{|c|}{ variance of uninformed trade } \\
\hline & .0566 & .0606 & .4332 & .1394 & .2323 \\
\hline & $(.02056)$ & $(.00230)$ & $(.01881)$ & $(.01259)$ & $(.00584)$ \\
\hline \multirow[t]{3}{*}{$c$} & \multicolumn{5}{|c|}{ cost of information $(\$)$} \\
\hline & 9.114 & 2.025 & 26.343 & 33.824 & 11.171 \\
\hline & $(1.3236)$ & $(.70085)$ & $(3.4378)$ & $(6.0060)$ & $(4.5367)$ \\
\hline \multicolumn{6}{|c|}{ ECONOMIC PARAMETERS } \\
\hline \multirow[t]{6}{*}{$\lambda$} & \multicolumn{5}{|c|}{ slope of specialist's pricing function } \\
\hline & .0202 & .0083 & .0019 & .0073 & .0031 \\
\hline & \multicolumn{5}{|c|}{ Adverse selection tariff for a 1.000 share order, $\$(\lambda \omega)^{2}$} \\
\hline & 20.20 & $8.30 \mid$ & 1.90 & $7.30 \mid$ & 3.10 \\
\hline & \multicolumn{5}{|c|}{ Adverse selection tariff for a 10.000 share order, $\$(\lambda \omega)^{2}$} \\
\hline & 2020.00 & 830.00 & 190.00 & 730.00 & 310.00 \\
\hline \multirow[t]{2}{*}{$\theta$} & \multicolumn{5}{|c|}{ ex-ante probability that a trader is informed } \\
\hline & .01239 & .02424 & .00311 & $.00: 300$ & .00630 \\
\hline \multirow[t]{4}{*}{$\sqrt{\sigma}$} & \multicolumn{5}{|c|}{ average size of an uninformed trade (shares) } \\
\hline & 238 & 246 & 658 & 373 & 482 \\
\hline & \multicolumn{5}{|c|}{ average size of an informed tracle (shares) } \\
\hline & 2124 & 1561 & 11775 & $\left(6 \$ 00^{\prime}\right.$ & 6052 \\
\hline \multirow[t]{2}{*}{$\sqrt{r}$} & \multicolumn{5}{|c|}{ average size of price shock $\$$} \\
\hline & $.154 \overline{1}$ & .1543 & .1073 & .1603 & .1250 \\
\hline \multirow[t]{2}{*}{$\sqrt{0}$} & \multicolumn{5}{|c|}{ average amount of noise $\$$} \\
\hline & $.2: 319$ & .9051 & .2336 & $20: 30$ & .4046 \\
\hline
\end{tabular}

Standard errors are given in parentheses directly below the point estimate s. 
Table 8: Transaction Cost Parameter Estimation for Alcoa Aluminum (AA)

\begin{tabular}{|c|c|c|c|}
\hline & NO TC & $\begin{array}{r}\text { FIXED } \\
\text { TC }\end{array}$ & $\begin{array}{r}\text { FIXED + VARIABLE } \\
\text { TC }\end{array}$ \\
\hline \multicolumn{4}{|c|}{ PARAMETERS } \\
\hline \multirow[t]{3}{*}{$\sigma$} & \multicolumn{3}{|c|}{ variance of uninformed trade } \\
\hline & .2084 & .2085 & 2085 \\
\hline & $(.00448)$ & $(.00449)$ & $(.00448)$ \\
\hline \multirow[t]{5}{*}{$c_{1}$} & \multicolumn{3}{|c|}{ variable transaction cost $(\$)$} \\
\hline & & .03210 & .03210 \\
\hline & & $(.00347)$ & $(.00320)$ \\
\hline & \multicolumn{3}{|c|}{ critical cutoff (shares) } \\
\hline & & * & 1400 \\
\hline \multirow[t]{3}{*}{$\lambda$} & \multicolumn{3}{|c|}{ slope of specialist's pricing function } \\
\hline & .00419 & .00250 & .00250 \\
\hline & $(.00070)$ & $(.00069)$ & \\
\hline \multirow[t]{3}{*}{$\theta$} & \multicolumn{3}{|c|}{ ex-ante probability that a trader is informed } \\
\hline & .09048 & .09050 & .090 .50 \\
\hline & $(.00767)$ & $(.00767)$ & \\
\hline \multirow[t]{5}{*}{$\sqrt{\sigma}$} & \multicolumn{3}{|c|}{ average size of an uninformed trade (shares) } \\
\hline & 457 & 457 & 4.57 \\
\hline & \multicolumn{3}{|c|}{ a.verage size of an informed trade (shares) } \\
\hline & 8049 & 8062 & 8049 \\
\hline & (369.395) & $(369.399)$ & \\
\hline
\end{tabular}

*: The nonlinear restrictions identify some, but not all structural parameters.

Standard errors are given in parentheses directly below the point estimates.

Test of linear rule vs. kinked alternative: $\left(\Upsilon^{2}(1)=10.700(>.99)\right)$. 


\section{Appendix 2. Integration of transaction costs}

Proof to lemma 2: An agent who has paid a cost $c$ to become informed now solves:

$$
M A X_{x_{i}} E\left[x_{i}\left(\delta-\lambda \omega-c_{1} I\right)-c_{2}\right]
$$

Differentiating with respect to $x_{i}$ and applying the projection theorem yields:

$$
x_{i}=\left[\frac{v(\delta+\epsilon)}{(v+\phi)}-c_{1} I\right] \frac{1}{2 \lambda} .
$$

An informed agent will not sell (buy) if he receives a signal greater (less) than zero.

Proof to lemma 2a: $\delta$ can be written as:

$$
\delta=E(\delta \mid \delta+\epsilon)+\xi
$$

Applying the projection theorem,

$$
\delta=\frac{v}{v+\phi}(\delta+\epsilon)+\xi
$$

To calculate the $\operatorname{var}[\delta \mid \delta+\epsilon]$, we first compute the variances of both sides of (20). This yields:

$$
v=\frac{v^{2}}{v+\phi}+\operatorname{var}(\xi)
$$

Since $E[\delta \mid \delta+\epsilon]$ is not random, $\operatorname{var}(\xi)=\operatorname{var}[\delta \mid \delta+\epsilon]$. Thus, $\operatorname{var}[\xi]=\frac{v \phi}{v+\phi}$. To obtain $E[(\delta+$ $\left.\epsilon)^{2} \mid \delta+\epsilon\right]$, recall that $\operatorname{var}[\delta \mid \delta+\epsilon]=E\left[\delta^{2} \mid \delta+\epsilon\right]-(E[\delta \mid \delta+\epsilon])^{2}$.

Then to obtain $E[\delta \epsilon \mid \delta+\epsilon]$, observe that $E\left[(\delta+\epsilon)^{2} \mid \delta+\epsilon\right]=E\left[\delta^{2} \mid \delta+\epsilon\right]+E[2 \delta \epsilon \mid \delta+\epsilon]+$ $E\left[\epsilon^{2} \mid \delta+\epsilon\right]=[\delta+\epsilon]^{2}$. Solving for $E\left[\epsilon^{2} \mid \delta+\epsilon\right]$ as above and then solving for $E[2 \delta \epsilon \mid \delta+\epsilon]$ yields the result.

\section{Simplifying assumptions used to produce figures 2-9.}

Under the assumptions that $\delta, \epsilon$, and $z$ are standard normal random variables,

$$
(\delta+\epsilon)^{*}=\sqrt{8 c_{2} \lambda}
$$

so that (17) reduces to:

$$
\int_{-\infty}^{\infty} \int_{\sqrt{8 c_{2} \lambda}-i}^{\infty}\left(3 \delta^{2}+2 \delta \epsilon-\epsilon^{2}\right) f_{\delta}(\delta) f_{\epsilon}(\epsilon) d \epsilon d \delta=8 \lambda\left[c+2 c_{2}\left(1-\Phi\left(2 \sqrt{c_{2} \lambda}\right)\right)\right] .
$$


Substituting $w=\delta+\epsilon$ and switching the order of integration, the left-hand side of (21) becomes:

$$
\begin{aligned}
& \frac{1}{2 \pi} \int_{\sqrt{8 c_{2} \lambda}}^{\infty} \int_{-\infty}^{\infty}\left[4 w \delta-w^{2}\right] e^{-\delta^{2} / 2} e^{-(w-\delta)^{2} / 2} d \delta d w= \\
& \quad \frac{1}{2 \pi} \int_{\sqrt{8 c_{2} \lambda}}^{\infty} 4 w e^{w^{2} / 4} \int_{-\infty}^{\infty} \delta e^{-(\delta-w / 2)^{2}} d \delta d w-\frac{1}{2 \pi} \int_{\sqrt{8 c_{2} \lambda}}^{\infty} w^{2} e^{w^{2} / 4} \int_{-\infty}^{\infty} e^{-(\delta-w / 2)^{2}} d \delta d w .
\end{aligned}
$$

Substituting $x=\sqrt{2} \delta-w / \sqrt{2}$, we obtain:

$$
\int_{\sqrt{8 c_{2} \lambda}}^{\infty} \int_{-\infty}^{\infty} \frac{e^{-w^{2} / 4}}{\pi} w\left(x+\frac{w}{\sqrt{2}}\right) e^{-x^{2} / 2} d x d w-\int_{\sqrt{8 c_{2} \lambda}}^{\infty} \frac{1}{2 \sqrt{\pi}} w^{2} e^{-w^{2} / 4} d w
$$

Noting that:

$$
\int_{-\infty}^{\infty} x e^{-x^{2} / 2} d x=0
$$

this reduces to

$$
\int_{\sqrt{8 c_{2} \lambda}}^{\infty} \frac{1}{2 \sqrt{\pi}} w^{2} \epsilon^{-w^{2} / 4} d w
$$

Integrating by parts, letting $u=w$ and $d v=w \epsilon^{-u^{2} / 4}$ and solving, the left-hand side equals:

$$
\left[\frac{8 c_{2} \lambda}{\pi}\right]^{\frac{1}{2}} e^{-2 c_{2} \lambda}+2\left(1-\Phi\left(2 \sqrt{c_{2} \lambda}\right)\right)
$$

Solving implicitly for $\lambda$ yields the result. The same integration techniques are adopted to solve the general problem with arbitrary variances, $v, \phi$ and $\sigma$.

\section{Appendix 3. Derivation of the unconditional joint density of $\Delta p_{s}$ and $\left|\omega_{s}\right|$} in the absence of transaction costs

Under weak regularity conditions (Amemiya [1985]), maximum likelihood maximizers $\{u(B)\}$ are consistent efficient estimators of $\left\{u\left(\beta_{0}\right)\right\}$ for mixtures of normal distributions. Let $L(\beta)=$ $L(\Delta p,|\omega|, \beta)$ be unconditional likelihood function for the price series for $\Delta p$ and $|\omega|$. The error, $e_{s}$ is conditionally normally distributed with mean zero and variance $\sigma_{j}$, where $j=1$ if the specialist faced an informed trader at time $s-t$ (probability $\theta$ ) and $j=2$ if the specialist faced an uninformed trader then (probability $1-\theta$ ). Let $I_{s}$, the bid-ask indicator, equal one if a trader is buying and minus one if he is selling. Finally, $\omega$ is conditionally normally distributed with mean zero and variance $\sigma_{w}$, where $w=3$ if the specialist faces an informed agent at time $s$ (probability $\theta$ ) and $w=4$ if that agent is uninformed (probability $1-\theta$ ). 
Given our assumptions, the conditional density of $\Delta p_{s}$ given past prices, bid-ask indicator, $I_{s}$, variance indicators, $j$ and $w$, is given by:

$$
f_{s}(\Delta p, \beta \mid I, j, \bullet)=\frac{1}{\sqrt{2 \pi \sigma_{j}}} e^{\frac{-\left(\Delta p_{s}-\lambda\left|\omega_{s}\right| I_{s}\right)^{2}}{2 \sigma_{j}}} .
$$

Integrating over the unconditional marginal distribution for the bid-ask indicator $I_{s}{ }^{8}$ yields:

$$
f_{s}(\Delta p, \beta \mid j, \bullet)=\frac{1}{2} \frac{1}{\sqrt{2 \pi \sigma_{j}}} e^{\frac{-\left(\Delta p_{s}-\lambda\left|\omega_{s}\right|\right)^{2}}{2 \sigma_{j}}}+\frac{1}{2} \frac{1}{\sqrt{2 \pi \sigma_{j}}} e^{\frac{-\left(\Delta p_{s}+\lambda\left|\omega_{s}\right|\right)^{2}}{2 \sigma_{j}}} .
$$

Glosten and Harris [1989] would write this as the unconditional density for $\Delta p_{s}$ in the absence of transaction costs. ${ }^{9}$ Here we must still integrate over the unconditional marginal density for $j$. In general, the probability a particular agent is informed is a function of the trade size. Define $\theta_{s}^{\prime}$ as the $\operatorname{pr}\left(\right.$ informed ||$\left.\omega_{s} \mid\right)$. Using Bayes' rule yields:

$$
\theta_{s}^{\prime}=\left(\theta \sqrt{\sigma_{4}} e^{\frac{-\omega^{2}}{2 \sigma_{3}}}\right)\left(\theta \sqrt{\sigma_{4}} e^{\frac{-\omega^{2}}{2 \sigma_{3}}}+(1-\theta) \sqrt{\sigma_{3}} e^{\frac{-\omega^{2}}{2 \sigma_{4}}}\right)^{-1}
$$

Now:

$$
\begin{array}{r}
f_{s}(\Delta p, \beta \mid w, \bullet)=\theta_{s-t}^{\prime}\left[\frac{1}{2} \frac{1}{\sqrt{2 \pi \sigma_{1}}} e^{\frac{-\left(\Delta p_{s}-\lambda\left|\omega_{s}\right|\right)^{2}}{2 \sigma_{1}}}+\frac{1}{2} \frac{1}{\sqrt{2 \pi \sigma_{1}}} e^{\frac{-\left(\Delta p_{s}+\lambda\left|\omega_{s}\right|\right)^{2}}{2 \sigma_{1}}}\right]+ \\
\left(1-\theta_{s-t}^{\prime}\right)\left[\frac{1}{2} \frac{1}{\sqrt{2 \pi \sigma_{2}}} e^{\frac{-\left(\Delta p_{s}-\lambda\left|\omega_{s}\right|\right)^{2}}{2 \sigma_{2}}}+\frac{1}{2} \frac{1}{\sqrt{2 \pi \sigma_{2}}} e^{\frac{-\left(\Delta p_{s}+\lambda\left|\omega_{s}\right|\right)^{2}}{2 \sigma_{2}}}\right] .
\end{array}
$$

Using information in the price series only, the unconditional likelihood function is:

$$
L(\beta)=\prod_{s=1}^{n} f_{s}(\Delta p \mid \bullet)
$$

\footnotetext{
${ }^{8}$ In this model, buying and selling is equally likely. However, this procedure can accommodate more complicated forms for this distribution, for example, serial correlation. Serial correlation might arise due to portfolio insurance strategies.

${ }^{9}$ However, they est.imate a model with transaction costs. In addition, their model places no structure on the probability the specialist faces an informed trader. Instead, they assume that traded quantities are normally distributed. Therefore, their unconditional likelihood function is an equally weighted average over $2^{n}$ unobserved bid-ask paths $\left(I_{1}, \ldots, I_{n}\right)$ of the conditional densities detailed above. That is:

$$
L(g(D) p, \beta)=\sum_{1}^{2^{n}} \frac{1}{2^{n}} \prod_{s=1}^{n} f_{s}(\Delta p, \beta \mid I, \bullet) .
$$
}

This can be computed recursively, as detailed in Glosten and Harris [1989]. 
However, the volume series provides additional information. Integrating over the unconditional marginal distribution for $w$, we find the unconditional density for wis:

$$
g_{s}((\omega) \mid \bullet)=\frac{\theta_{s}^{\prime}}{\sqrt{2 \pi \sigma_{3}}} e^{\frac{-\omega^{2}}{2 \sigma_{3}}}+\frac{\left(1-\theta_{s}^{\prime}\right)}{\sqrt{2 \pi \sigma_{4}}} e^{\frac{-\omega^{2}}{2 \sigma_{4}}} .
$$

Unfortunately, it is not appropriate to write some $h_{s}=f_{s} g_{s}$ and then write the unconditional likelihood function as $\prod_{s=1}^{n} h_{s}(\Delta p|\omega| \bullet)$. The reason is that lagged $\omega$ 's determine $\sigma_{j}$ and current $\omega$ 's determine the distribution for $\sigma_{w}$. The unconditional likelihood function $L$ has a recursive structure.

Define $\int_{s}^{* *}$ as the conditional joint density of $\Delta p_{s}$ and $\omega_{s}$, where the first superscript indicates whether the trader at time $s-t$ was informed and the second superscript indicates whether the trader a.t time $s$ is informed. Let $*=i$ if a trader is informed and $u$ otherwise. Thus:

$$
\begin{aligned}
& f_{s}^{i i}=\frac{\theta_{s-t}^{\prime}}{2 \sqrt{2 \pi \sigma_{1}}} \epsilon^{\frac{-\left(\Delta p_{s}-\lambda\left|\omega_{s}\right|\right)^{2}}{2 \sigma_{1}}} \frac{\theta_{s}^{\prime}}{\sqrt{2 \pi \sigma_{3}}} e^{\frac{-\omega_{s}^{2}}{2 \sigma_{3}}}+\frac{\theta_{s-t}^{\prime}}{2 \sqrt{2 \pi \sigma_{1}}} e^{\frac{-\left(\Delta p_{s}+\lambda \mid \omega_{s}\right)^{2}}{2 \sigma_{1}}} \frac{\theta_{s}^{\prime}}{\sqrt{2 \pi \sigma_{3}}} e^{\frac{-\omega_{s}^{2}}{2 \sigma_{3}}}, \\
& f_{s}^{u i}=\frac{\left(1-\theta_{s-t}^{\prime}\right)}{2 \sqrt{2 \pi \sigma_{2}}} e^{\frac{-\left(\Delta r_{s}-\lambda\left|\omega_{s}\right|\right)^{2}}{2 \sigma_{2}}} \frac{\theta_{s}^{\prime}}{\sqrt{2 \pi \sigma_{3}}} e^{\frac{-\omega_{s}^{2}}{2 \sigma_{3}}}+\frac{\left(1-\theta_{s-t}^{\prime}\right)}{2 \sqrt{2 \pi \sigma_{2}}} e^{\frac{-\left(\Delta p_{s}+\lambda\left|\omega_{s}\right|\right)^{2}}{2 \sigma_{2}}} \frac{\theta_{s}^{\prime}}{\sqrt{2 \pi \sigma_{3}}} e^{\frac{-\omega_{s}^{2}}{2 \sigma_{3}}}, \\
& f_{s}^{i u}=\frac{\theta_{s-t}^{\prime}}{2 \sqrt{2 \pi \sigma_{1}}} \mathrm{r}^{\frac{-\left(\Delta p_{s}-\lambda\left|\omega_{s}\right|\right)^{2}}{2 \sigma_{1}}} \frac{\left(1-\theta_{s}^{\prime}\right)}{\sqrt{2 \pi \sigma_{4}}} e^{\frac{-\omega_{s}^{2}}{2 \sigma_{4}}}+\frac{\theta_{s-t}^{\prime}}{2 \sqrt{2 \pi \sigma_{1}}} e^{\frac{-\left(\Delta p_{s}+\lambda\left|\omega_{s}\right|\right)^{2}}{2 \sigma_{1}}} \frac{\left(1-\theta_{s}^{\prime}\right)}{\sqrt{2 \pi \sigma_{4}}} e^{\frac{-\omega_{s}^{2}}{2 \sigma_{4}}}, \\
& f_{s}^{u u}=\frac{\left(1-\theta_{s-t}^{\prime}\right)}{2 \sqrt{2 \pi \sigma_{2}}} e^{\frac{-\left(\Delta p_{s}-\lambda\left|\omega_{s}\right|\right)^{2}}{2 \sigma_{2}}} \frac{\left(1-\theta_{s}^{\prime}\right)}{\sqrt{2 \pi \sigma_{4}}} \epsilon^{\frac{-\omega_{s}^{2}}{2 \sigma_{4}}}+\frac{\left(1-\theta_{s-t}^{\prime}\right)}{2 \sqrt{2 \pi \sigma_{2}}} e^{\frac{-\left(\Delta p_{s}+\lambda\left|\omega_{s}\right|\right)^{2}}{2 \sigma_{2}}} \frac{\left(1-\theta_{s}^{\prime}\right)}{\sqrt{2 \pi \sigma_{4}}} e^{\frac{-\omega_{s}^{2}}{2 \sigma_{4}}} \text {. }
\end{aligned}
$$

Now define $f_{s}^{\iota}=f_{s}^{i i}+f_{s}^{u i}$ and $f_{s}^{u}=\int_{s}^{i u}+\int_{s}^{u u}$. Also. let $L_{1}=f_{1}^{i}+f_{1}^{u}$. Now:

$$
L_{2}=f_{1}^{i}\left(f_{2}^{i i}+f_{2}^{i u}\right)+f_{1}^{u}\left(\int_{2}^{u i}+f_{2}^{u u}\right)
$$

In gencral:

$$
L_{s}=\int_{s-t}^{i}\left(\int_{s}^{i i}+\int_{s,}^{\prime \prime \prime}\right)+\int_{s-1}^{u}\left(f_{s}^{u i}+\int_{s}^{u u}\right),
$$

where:

$$
\int_{s}^{i}=\int_{s-1}^{i} f_{s}^{u i}+\int_{s-t}^{u} f_{s}^{u i} .
$$

and.

$$
\int_{s}^{u}=\int_{s-1}^{i} \int_{s}^{i u}+f_{s-1}^{u} f_{s}^{u u} .
$$

Indexing by transaction mumber rather than by transaction time yields:

$$
I_{n}=\int_{n-1}^{1}\left(\int_{n}^{i i}+\int_{n}^{\prime \prime \prime}\right)+\int_{n-1}^{\prime \prime}\left(\int_{n}^{u \prime}+\int_{n}^{u u}\right),
$$


where $L_{n}=L(\Delta p,|\omega| \mid \bullet)$. If there is a break in the transaction price series for any reason, e.g. the end of the day, we restart the iterative process. That is, $\theta_{s-t}^{\prime}$ is reset to $\theta$. Thus, the $\log$ of the likelihood function becomes the sum of the log likelihoods over the regions where the iteration occurs. Were there $M$ breaks, the log of the likelihood, $L L$, would be represented by:

$$
L L=\sum_{m=1}^{M} \log \left[L_{n_{n}}\right]
$$

This assumption makes the most sense overnight, where there is a long interval without trade: Information release continues overnight. When a break occurs in the middle of the day, we prefer to throw away information rather than pollute the time series by introducing observations which may be generated by a different forcing process.

In general, the likelihood function depends on the parameters $\lambda, \sigma_{1}, \sigma_{2}, \sigma_{3}, \sigma_{4}$, and $\theta$. However, these are functions of structural parameters, $v, \phi, c, \sigma$, and $k$, a scaling constant which is needed because time periods are not necessarily scaled in minutes. In the estimation, we finesse this issue by assuming that there is a single innovation between trades.

Recall:

$$
\lambda=\frac{v^{2}}{4 c(v+\phi)} ; \beta=\frac{2 c}{v} ; \quad \theta=\frac{\sigma v^{2}}{\sigma v^{2}+4 c^{2}(v+\phi)} .
$$

In addition, $\sigma_{1}=E\left[(\delta-\lambda \omega)^{2} \mid\right.$ in formed trader $]$ and $\sigma_{2}=E\left[(\delta-\lambda \omega)^{2} \mid\right.$ uninformed trader $]$. By substituting for $\lambda$ and recalling that $\sigma_{3}=\beta^{2}(v+\phi)$ and $\sigma_{4}=\sigma$, we obtain:

$$
\begin{gathered}
\sigma_{1}=k v t-\frac{3 v^{2}}{4(v+\phi)} \\
\sigma_{2}=k v t-\frac{v^{4} \sigma}{16 c^{2}(r+\phi)^{2}} .
\end{gathered}
$$

\section{Appendix 4. Derivation of the likelihood function used in table 1}

Variable transaction costs are not considered $\left(c_{1}=0\right)$. Also, $e_{s}$ has constant variance. As a result, this likelihood function need not be derived recursively. Recall that $J_{t}=1$ only if $\omega$ exceeds the cutoff $\omega^{*}$. As a diagnostic, we subtract $\mu_{0}+\mu_{1} t$ to check for deterministic components to price changes. Therefore, $-2 \log [1(p)]-($ constant $)$ can be written as:

$$
-2 \log L=\sum_{t=1}^{n}\left\{\log \left(\operatorname{var}\left(e_{t}\right)\right)-2 \log \left[\epsilon^{\frac{\left(\Delta p-\lambda|\omega| J_{t}-\mu_{0}-\mu_{1} t\right)^{2}}{2 \operatorname{var}(e)}}+e^{\frac{\left(\Delta p+\lambda|\omega| J_{t}-\mu_{0}-\mu_{1} t\right)^{2}}{2 \operatorname{var}(e)}}\right]\right\}
$$


Define the expression in square brackets as $T 1+T 2$, where $T 1$ is the first exponential, and $T 2$ the second. Further, let $T 1=e^{\frac{-E 1}{2 v a r(e)}}$ and $T 2=e^{\frac{-E 2}{2 \operatorname{vir}(e)}}$. Taking the derivatives with respect to $\operatorname{var}(e), \mu_{0}, \mu_{1}$, and $\lambda$, we obtain:

$$
\begin{aligned}
\sum_{t=1}^{n} \frac{-2 \partial l_{t}}{\partial \lambda} & =\sum_{t=1}^{n} \frac{-2|\omega| J_{t}}{(T 1+T 2) \operatorname{var}(e)}(E 1 * T 1-E 2 * T 2)=0, \\
\sum_{t=1}^{n} \frac{-2 \partial l_{t}}{\partial \mu_{0}} & =\sum_{t=1}^{n} \frac{-2}{(T 1+T 2) \operatorname{var}(e)}(E 1 * T 1+E 2 * T 2)=0, \\
\sum_{t=1}^{n} \frac{-2 \partial l_{t}}{\partial \operatorname{var}(e)} & =\sum_{t=1}^{n}\left[1-\frac{-1}{(T 1+T 2)(\operatorname{var}(e))^{2}}\left(E 1^{2} T 1+E 2^{2} * T 2\right)\right]=0 .
\end{aligned}
$$

All four parameters are theoretically identified, except when $\lambda$ approaches zero. Then, $T 1$ approaches $T 2$, and (25) collapses to zero, leaving the first derivative matrix short of full rank.

\section{Appendix 5. Derivation of the likelihood function with transaction costs}

Recall that $J_{s}=1$ if $\omega>\omega^{*}$. Let $K_{s}=1$ if $I_{s}=1$ and $I_{s-t}=-1 ; K_{s}=-1$ if $I_{s}=-1$ and $I_{s-t}=1$; and $K_{s}=0$ otherwise. That is, there is no bid-ask "bounce" if $I_{s-t}=I_{s}$.

We begin by writing the conditional density for $\Delta p_{s}$ :

$$
f_{s}^{\bullet \bullet}=f_{s}\left(\Delta p, \beta \mid I_{s}, I_{s-t}, j_{s}, \bullet\right)=\frac{1}{\sqrt{2 \pi \sigma_{i}}} e^{\frac{\left(\Delta p_{s}-\lambda\left|\omega_{s}\right| I_{s} J_{s}-2 c_{1} K s\right)^{2}}{2 \sigma_{j}}},
$$

where $\bullet=b$ if $i=1$ and $s$ otherwise. Gilosten and Harris [1989] have $J_{s}=1$, and do not distinguish between informed and uninformed traders. They need only weight the $2^{n}$ possible bid-ask paths to construct the likelihood function for $\Delta p$.

Here, estimation is complicated by the dependence of $\sigma_{j}$ on past realizations of volume, $\omega_{s-t}$, due to the unobserved identity (informed or uninformed) of the trader in both at time $t$ and at time $t-1$. Thus, we also weight over all possible sequences of identities. We write the likelihood function in pieces in order to highlight its recursive construction. Define

$$
f_{n}^{\bullet \cdots \bullet}=\frac{p r(\bullet \bullet \bullet)}{8 \pi \sqrt{\sigma_{j, n-1} \sigma_{j, n}}} e^{\frac{-\omega_{s}^{2}}{2 \sigma_{j}}} e^{\frac{-\left(\Delta p_{s}-\lambda\left|\omega_{s}\right| I_{s} J_{s}-2 c_{1} K_{s}\right)^{2}}{2 \sigma_{j}}},
$$

where the four arguments in the superscript of $f_{n}^{\bullet \bullet \bullet}$ are: $\{i, u\}_{n-1},\{i, u\}_{n},\{b, s\}_{n-1},\{b, s\}_{n}$. The first argument is $i$ if an informed agent traded in period $n-1$ and $u$ otherwise; the second argument is $i$ if an informed agent traded in period $n$ and $u$ otherwise; the third argument is $b$ if an agent bought in period $n-1$ and $s$ otherwise; and the fourth argument is $b$ if an agent 
bought in period $n$ and $s$ otherwise. $\operatorname{pr}(\bullet \bullet \bullet)$ is the probability of a particular state occurring. Note that when $\omega$ is below the critical cutoff, the probability of an informed trader must be zero. The recursive structure is similar to that given in appendix 3 , but there are now more terms:

$$
\begin{aligned}
L_{n}= & f_{n-1}^{i b}\left[f_{n}^{i i b b}+f_{n}^{i i b s}+f_{n}^{i u b b}+f_{n}^{i u b s}\right]+f_{n-1}^{i s}\left[f_{n}^{i i s b}+f_{n}^{i i s s}+f_{n}^{i u s b}+f_{n}^{i u s s}\right]+ \\
& f_{n-1}^{i b}\left[f_{n}^{u i b b}+f_{n}^{u i b s}+f_{n}^{u u b b}+f_{n}^{u u b s}\right]+f_{n-1}^{i b}\left[f_{n}^{u i s b}+f_{n}^{u i s s}+f_{n}^{u u s b}+f_{n}^{u u s s}\right]
\end{aligned}
$$

where:

$$
\begin{gathered}
f_{n}^{i b}=f_{n-1}^{i b} f_{n}^{i i b b}+f_{n-1}^{i s} f_{n}^{i i s b}+f_{n-1}^{u b} f_{n}^{u i b b}+f_{n-1}^{u s} f_{n}^{u i s b}, \\
f_{n}^{i s}=f_{n-1}^{i b} f_{n}^{i i b s}+f_{n-1}^{i s} f_{n}^{i i s s}+f_{n-1}^{u b} f_{n}^{u i b s}+f_{n-1}^{u s} f_{n}^{u i s s}, \\
f_{n}^{u b}=f_{n-1}^{i b} f_{n}^{i u b b}+f_{n-1}^{i s} f_{n}^{i u s b}+f_{n-1}^{u b} f_{n}^{u u b b}+f_{n-1}^{u s} f_{n}^{u u s b}, \\
f_{n}^{u s}=f_{n-1}^{i b} f_{n}^{i u b s}+f_{n-1}^{i s} f_{n}^{i u s s}+f_{n-1}^{u b} f_{n}^{u u b s}+f_{n-1}^{u s} f_{n}^{u u s s} .
\end{gathered}
$$


Admati, A., and P. Pfleiderer, 1988, "A Theory of Intraday Patterns", Review of Financial Studies, 1, 3-40.

Amemiya, T., 1985, Advanced Econometrics, Harvard University Press.

Bernhardt, D., and E. Hughson, 1992, "Trade in Thin Markets", unpublished manuscript, Queen's University and the California Institute of Technology.

Bernhardt, D., and E. Hughson, 1992, "Discrete Pricing and Institutional Design", unpublished manuscript, Queen's University and the California Institute of Technology.

Bernhardt, D., and E. Hughson, 1992, "A Simultaneous Equations Estimation of an Intraday Trading Model", unpublished manuscript, C'alifornia Institute of Technology.

Bronfman, C.., 1990, "Untitled Manuscript", unpublished manuscript, University of Arizona.

DeGroot, M.. 1975, Probability and Statistics, Addison Wesley Publishing Company Inc.

Easley, D., and M. O'Hara, 1987, "Prices. tradesize, and Information in securit ies markets", Journal of Financial Economics, 19, 69-90.

Foster F.D., and S. Viswanathan, 1988, "Interday variations in Volumes, Spreads, and Variances, I: Theory”, unpublished manuscript. Duke University.

_- . 1990, "Variations in Volumes. Variances, and Trading Costs", Review of Financial Studies, 3, 593-624.

Gilosten. L., 1987. "Components of the Bid-Ask Spread and the Statistical Properties of Transaction Prices". Journal of Finance, 42, 129:3-1307.

Glosten, L, and L. Harris, 1989, "Estimating ('omponents of the Bid-Ask Spread", Journal of Financial Economics, 21, 123-142.

Glosten, L., and P. Milgrom, 1985, "Bid. Ask and Transaction Prices in a Market with Heterogeneously Informed Traders", Journal of Financial Economics, 14, 71-100.

Hagerty, K. 1986, "Equilibrium Bid-Ask Spreads in Markets with Multiple Assets", unpublished manuscript, Northwestern University. 
Harris, L., 1985, "A Transaction Data Study of Weekly and Intradaily Patterns in Stock Returns", Journal of Financial Economics, 16, 99-117.

___ 1986, "Estimation of "True" Stock Price Variances and Bid-Ask Spreads from Discrete Observations", unpublished manuscript, University of Southern California.

— 1989, "Stock Price Clustering, Discreteness, and Bid/Ask Spreads", unpublished manuscript, NYSE Working Paper 89-01.

Hasbrouck, J., 1991, "Measuring the Information Content of Stock Trades", Journal of Finance, 46, 179-208.

Hasbrouck, J., and G. Sofianos, 1992, "The Trades of Market Makers: An Analysis of NYSE Specialists", unpublished manuscript, New York University and the New York Stock Exchange.

Judge, G.G., W. E. Griffiths, R. C. Hill, Lutkepohl, and T. Lee, 1985, The Theory and Practice of Econometrics, The Wiley Series in Probability and Mathematical Statistics.

Kyle, A., 1985. "Continuous Auctions and Insider Trading", Econometrica, 53, 1315-1335.

Lee, C. and M. Ready, 1991, "Inferring Trade Direction from Intraday Data", Journal of Finance, 45, 733-746.

Madhavan, A. and S. Smidt, 1992, "An Analysis of Daily Changes in Specialist Inventories and Quotations", unpublished manuscript, University of Pennsylvania and Cornell University.

Roll, R., 1984, "A Simple Measure of the Effective Bid-Ask Spread in an Efficient Market", Journal of Finance, 39. 1127-1139.

Stoll, H, and R. Whaley, 1989, "Stock Market Structure and Volatility", unpublished manuscript, Vanderbilt University and Duke University.

Terry, E., 1986. "End of the Day Returns and the Bid-Ask Spread", unpublished manuscript, Stanford University.

Wood, R., T. McInish, and J.K. Ord, 1985. "Investigation of Transactions Data for NYSE Stocks", Journal of Finance, 50, 723-741. 
Volume or Variance

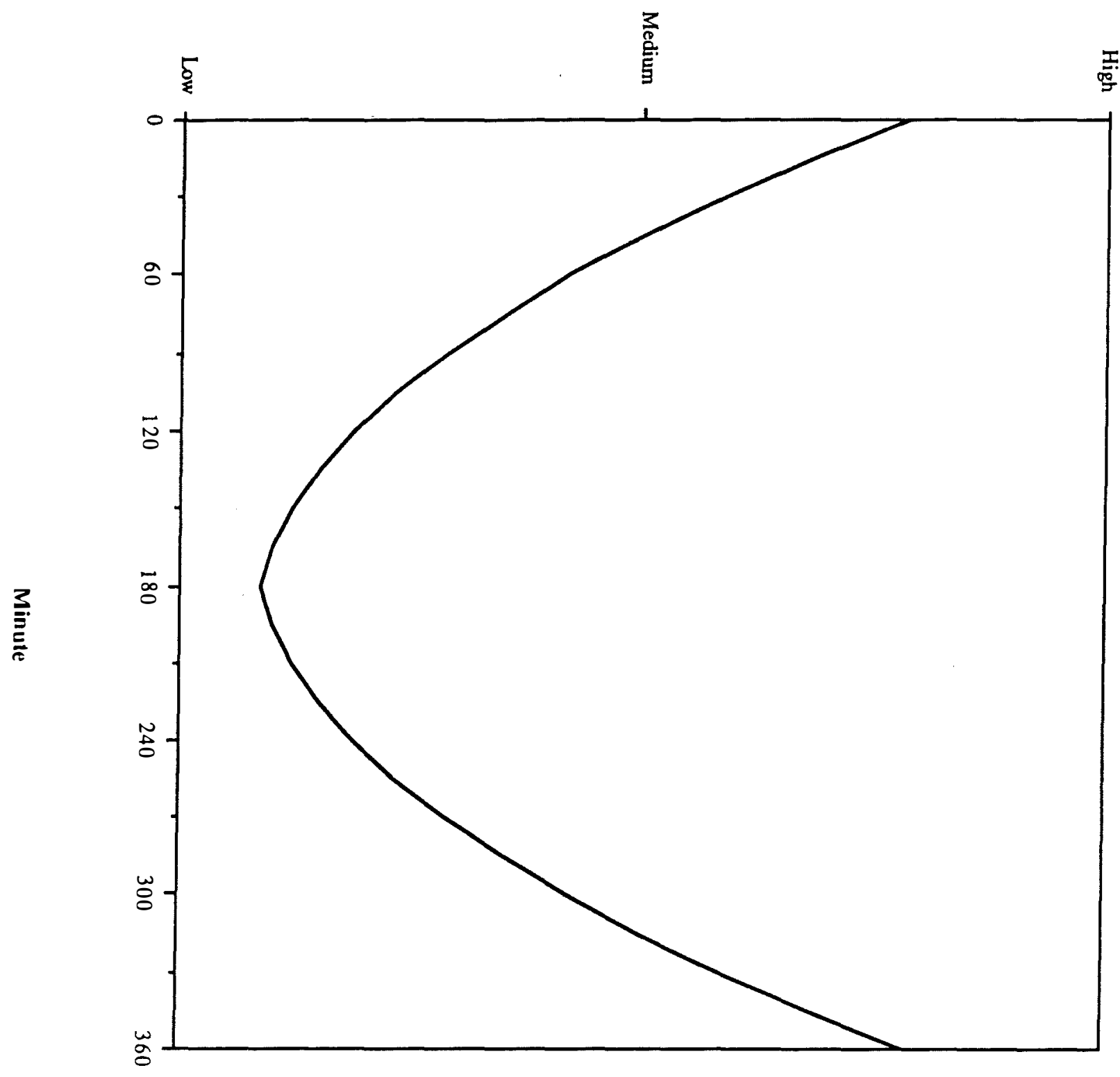

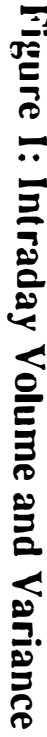


Figure 2: Share Transaction Price with Transaction Cost

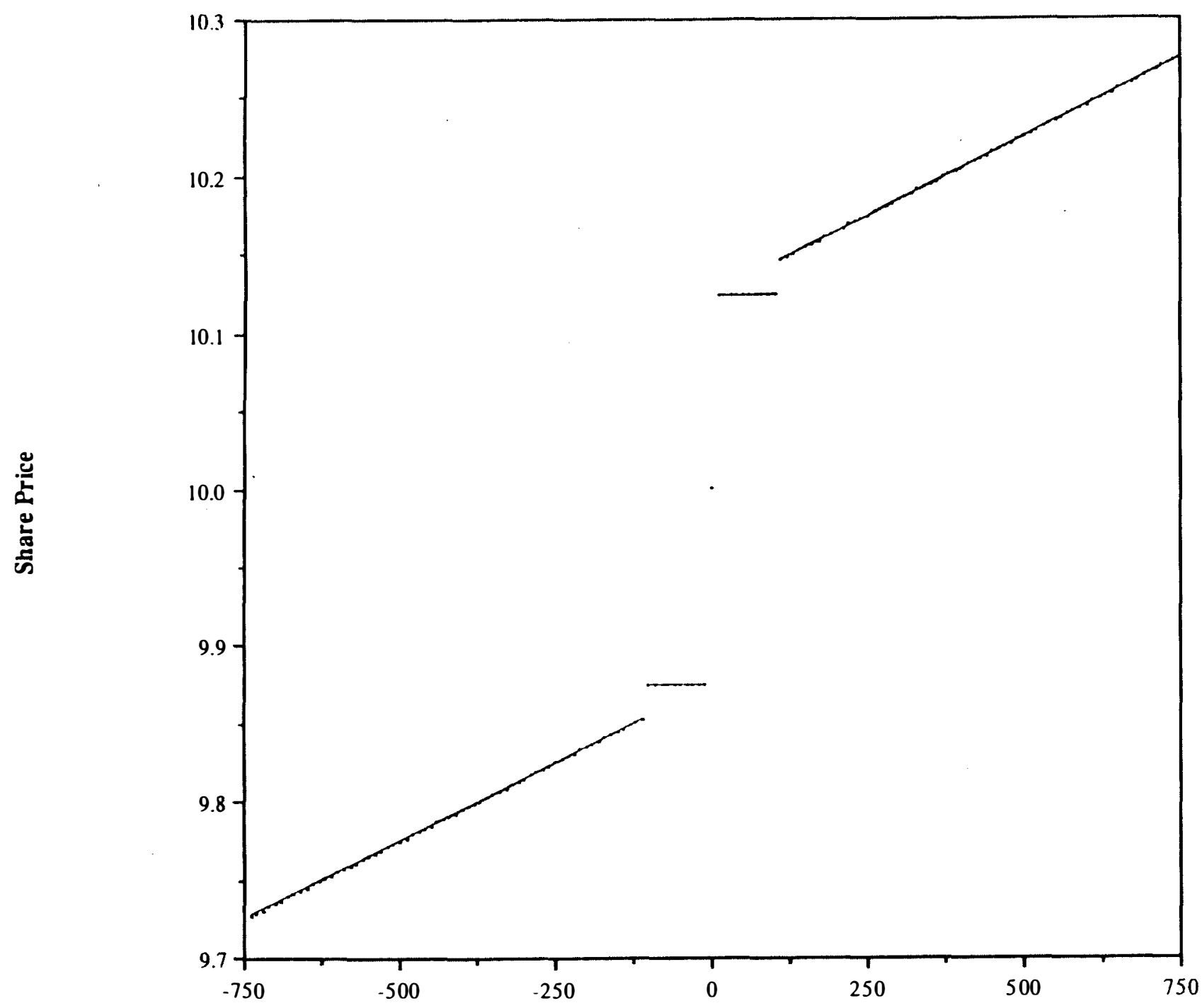

Trade Quantity (negative $=$ sell) 
Figure 3: Lambda, Pi/Eta vs. Trading Costs, $c=.5$

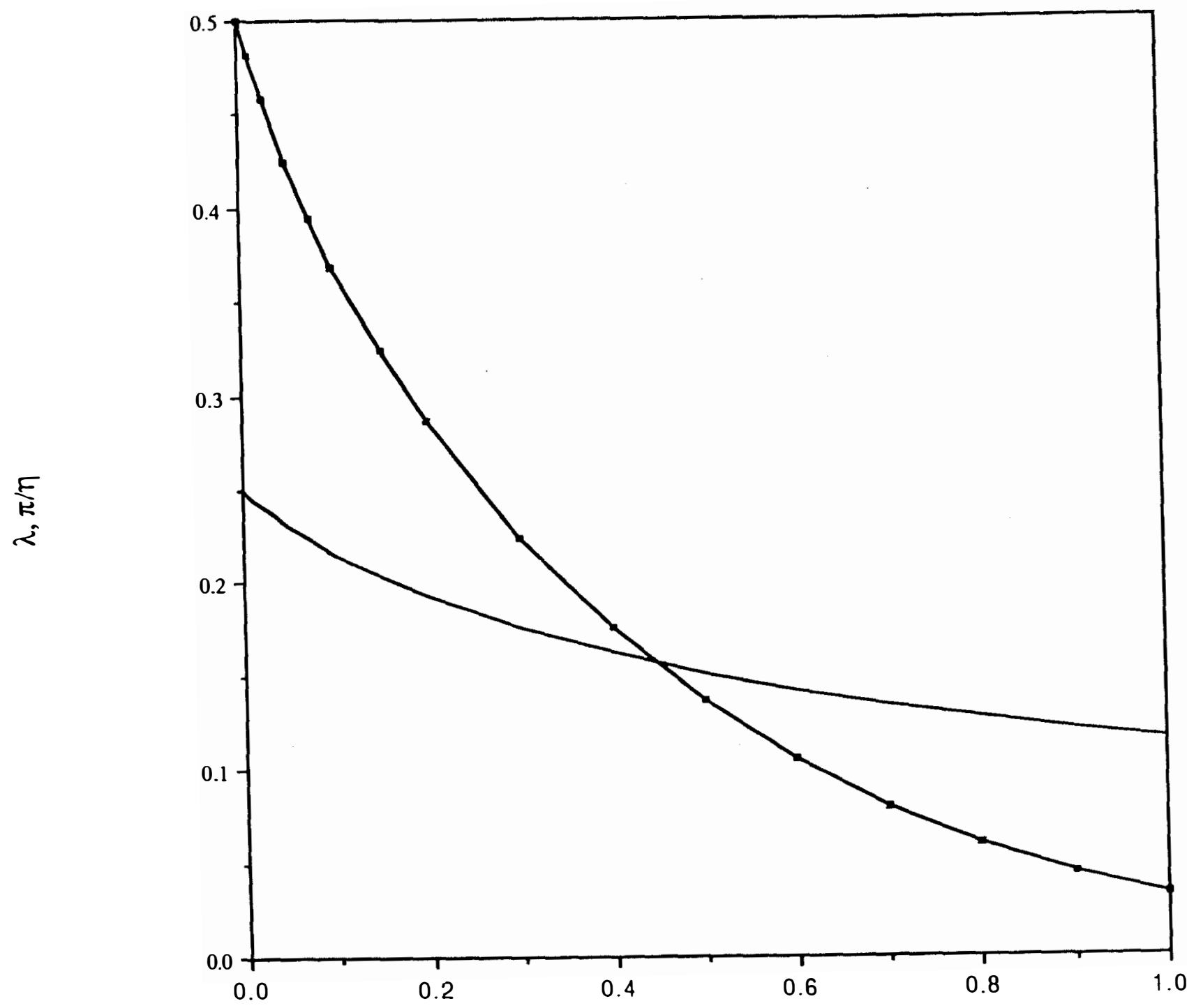

$-\lambda$

$\rightarrow \pi / \eta$

$z, \delta, \in \sim N(0,1) ; C 1=0$ Trading costs are fixed only.

Trading Costs $(\mathrm{c} 1+\mathrm{c} 2)$ 
Figure 4: Lambda, Pi/Eta vs. Trading Costs, $c=1$.

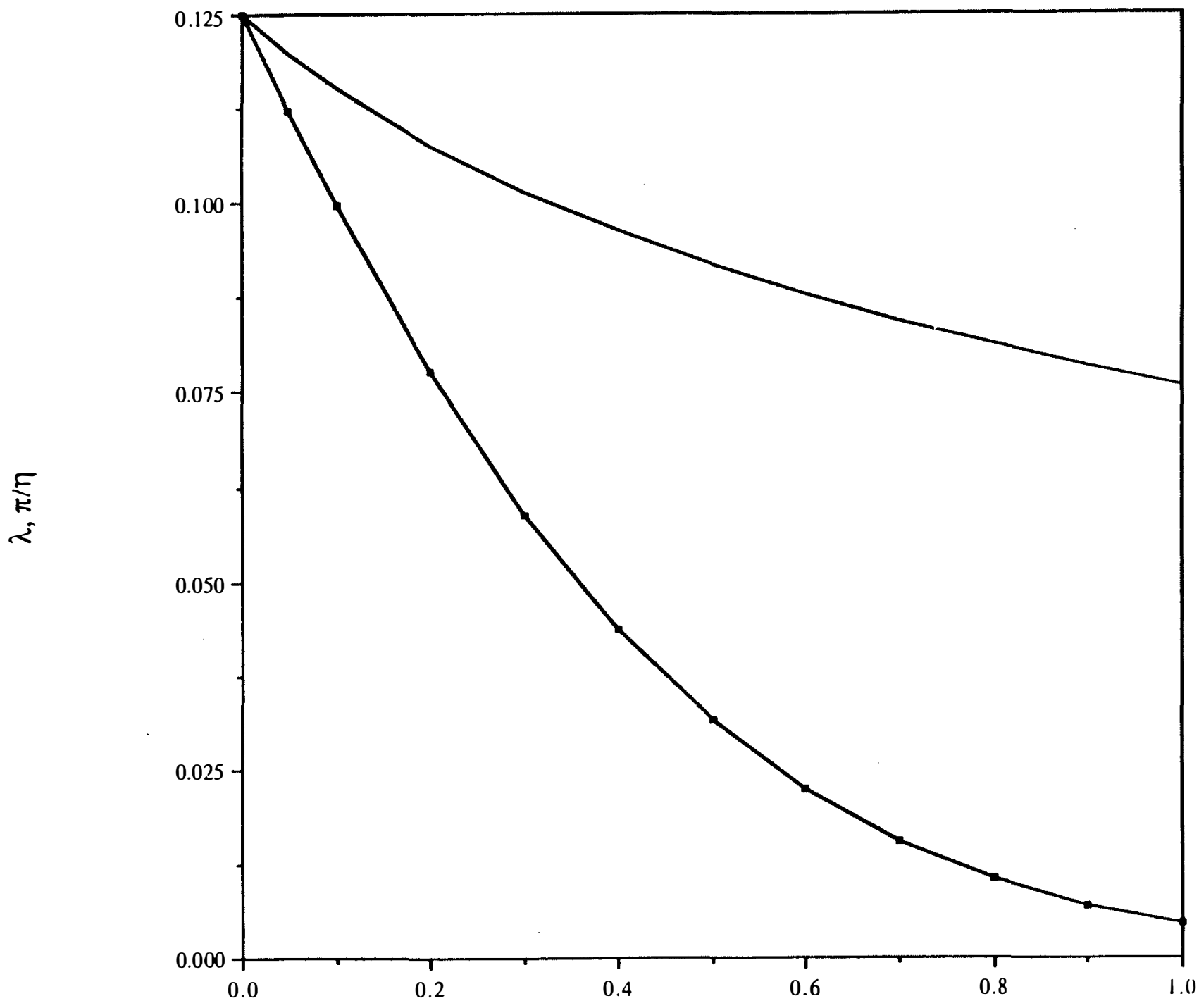

$-\lambda$

$Z, \delta, \in \sim N(0,1) ; C 1=0$ Trading costs are fixed only.

Trading ('usts $(c)+c 2)$ 
Figure 5a: Prob(No Trade|Informed) vs. Trading Costs, c=.5

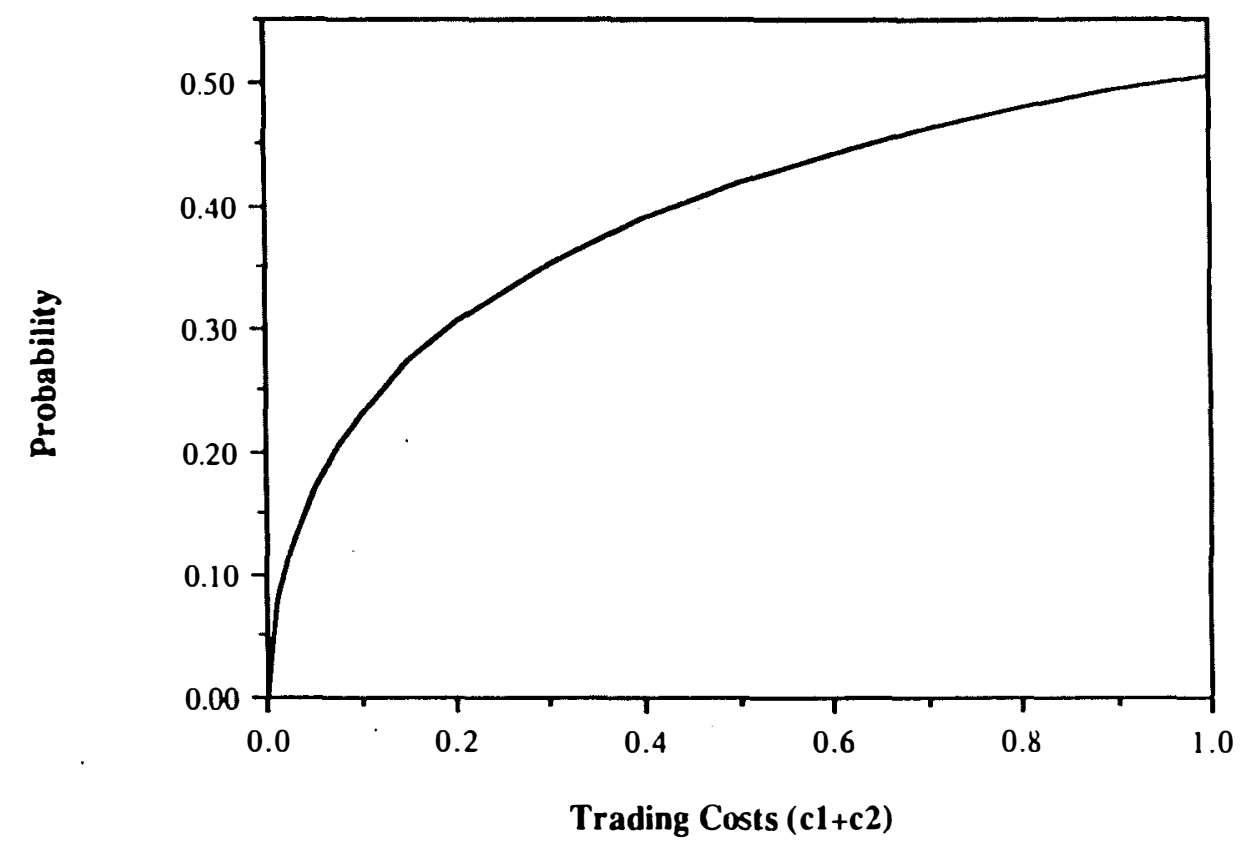

Probobility signal is smoll enough that informed cannot recoup trading costs by triding.

$z, \delta, \in \sim N(0,1) ; C 1=0$ Trading costs are fixed only.

Figure 5b: Minimum Informed Trade Size vs. Trading Costs, c=.5

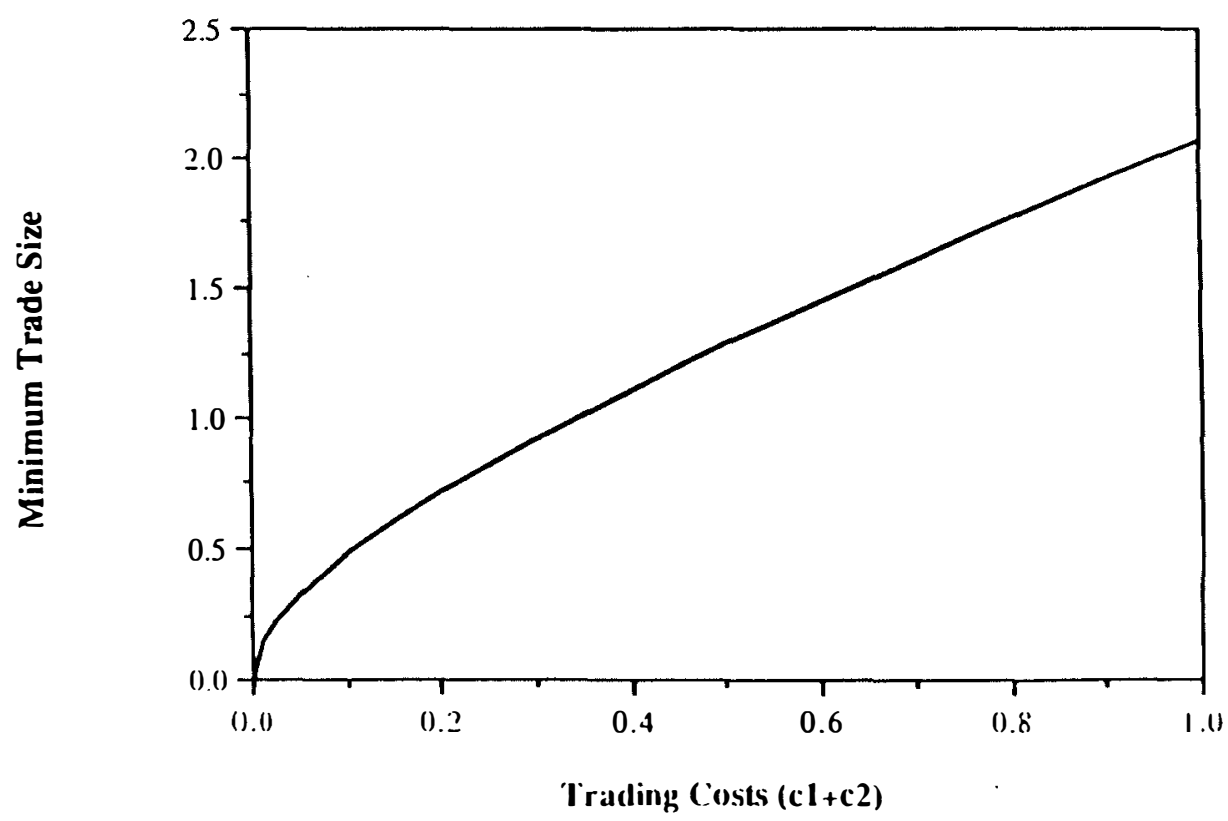

Quantity below which trode by iriforined is unficifitable. 
Figure 6a: Prob(No Trade|Informed) vs. Trading Costs, $c=1.0$

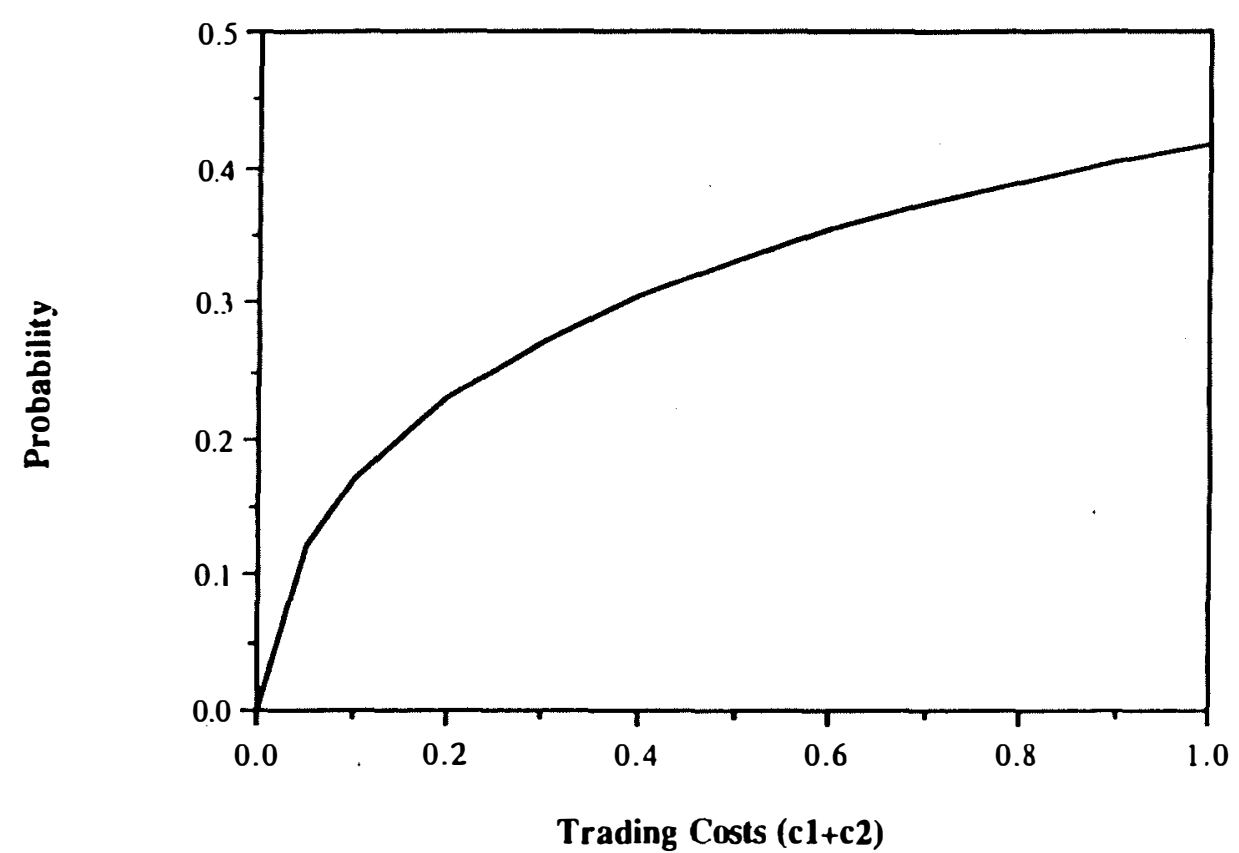

Probability sigial is inioll enough that informed caninot recoup fixed costs by trading.

$z, \delta, \in \sim N(0,1) ; C 1=0$ Trading costs arc fixed cin!!

Figure 6b: Minimum Informed Trade Size vs. Trading Costs, $c=1.0$

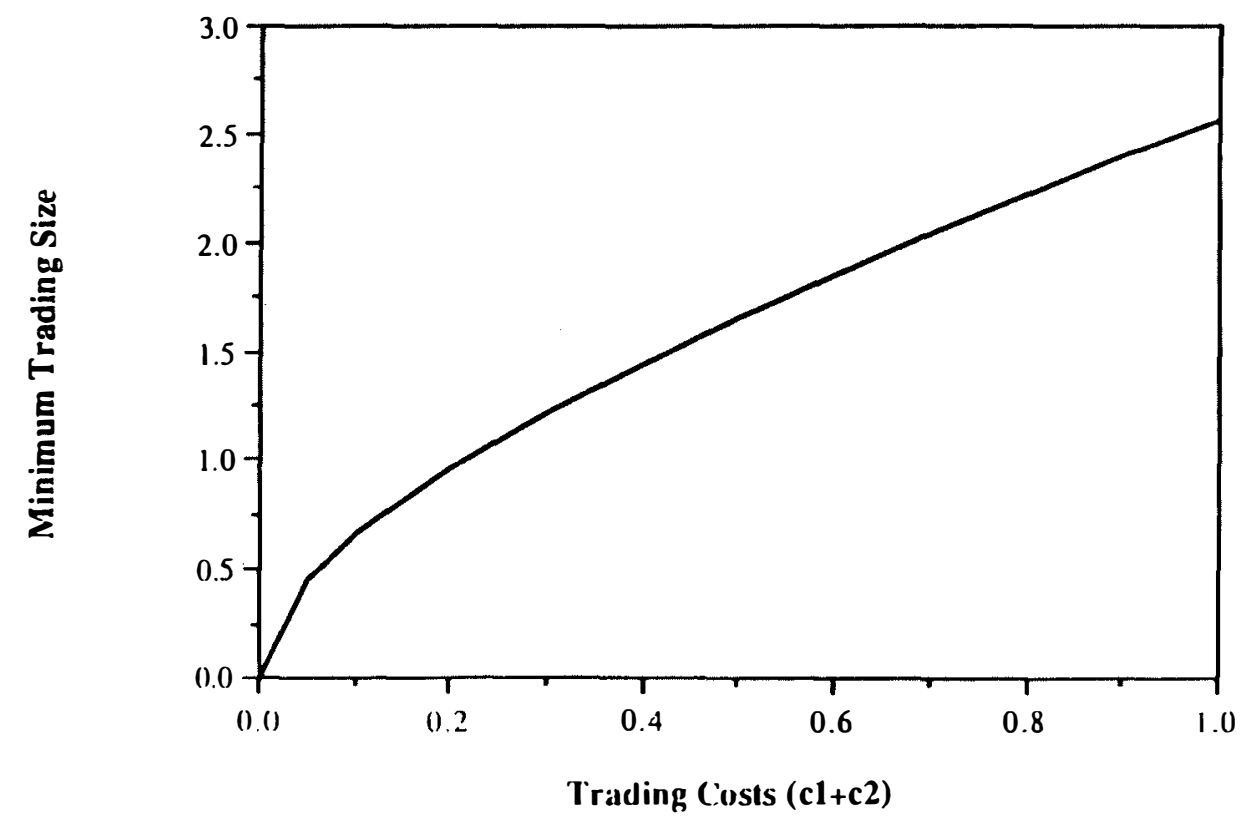

Quantity belows which, trode by informed is unis table. 
Figure 7a: Lambda vs c/c*

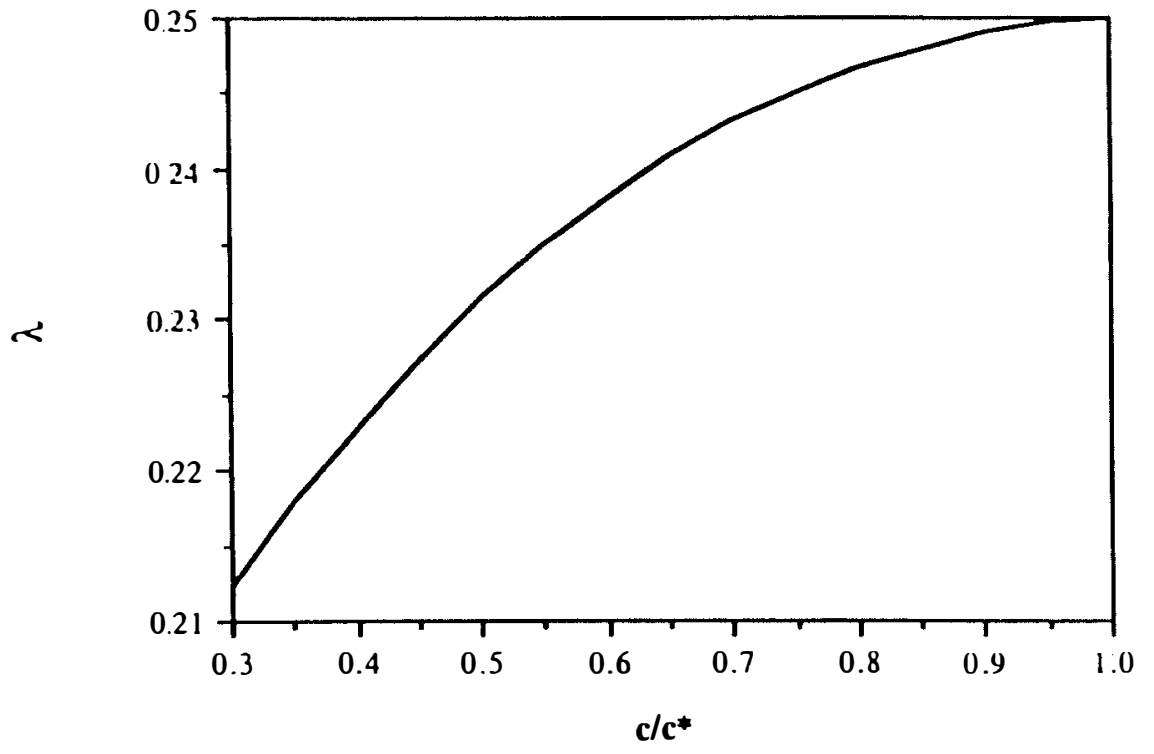

Lambda rises as inforniation acquisition cost comprises a himer.fraction of fixed costs.

$z, \delta, \epsilon \sim N(0,1) ; C 1=0$

Troding costs are fixed oni.

Figure 7b: Pi/Eta vs. c/c*

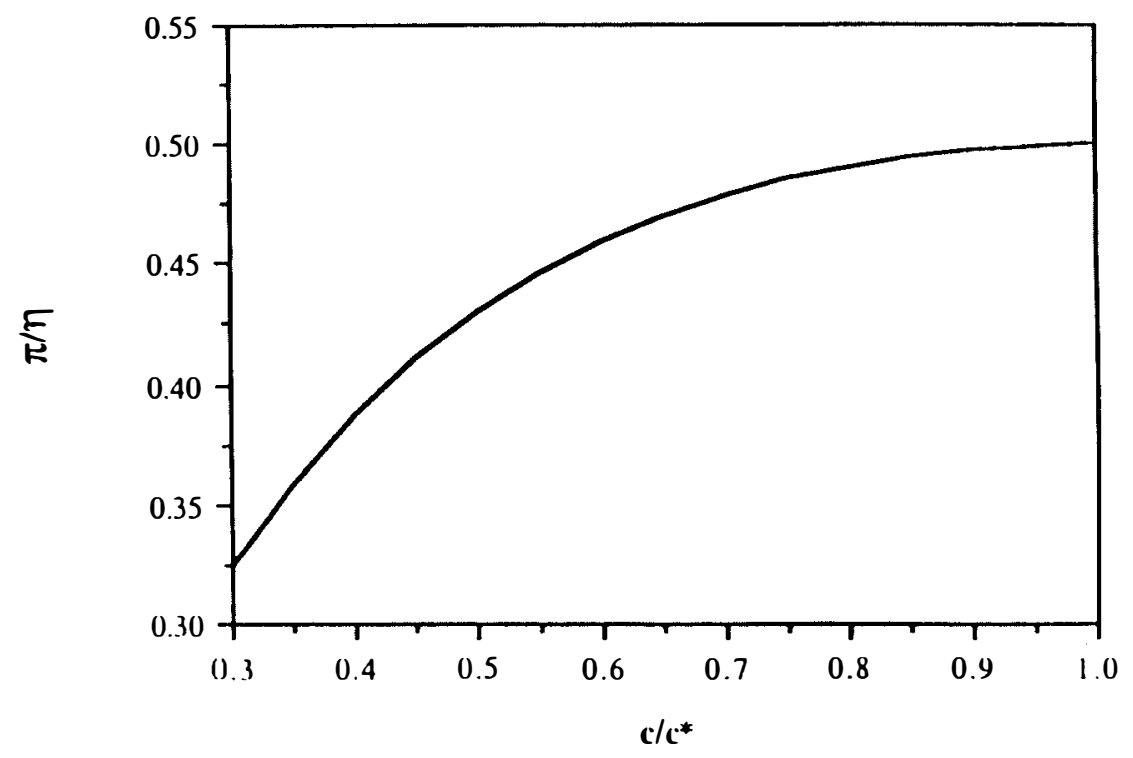

Probability specialist fuces an inforined trader also rises os acquisition cost comprises a larger fraction of fixed costs. 
Figure 8a: Prob(No Trade|Informed) vs. c/c*

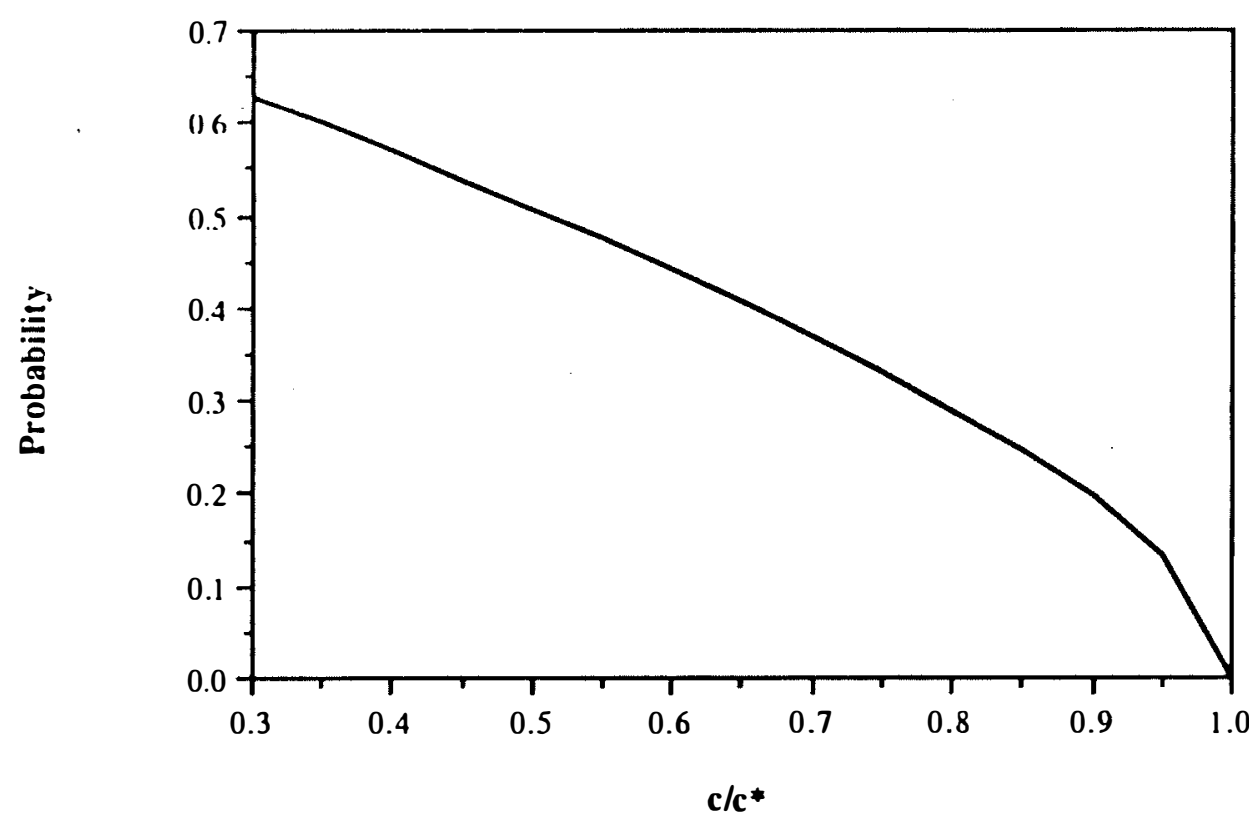

Tine sostablity aia nferriafel trader will wolk ariay without troding decreases as tradiria costs form a smalier icirt of fixed costs.

$z, \delta, \in \sim N(0,1) ;(1-0)$ Tiluding costs are fixed only.

Figure 8b: Minimum Informed Trade Size vs. c/c*

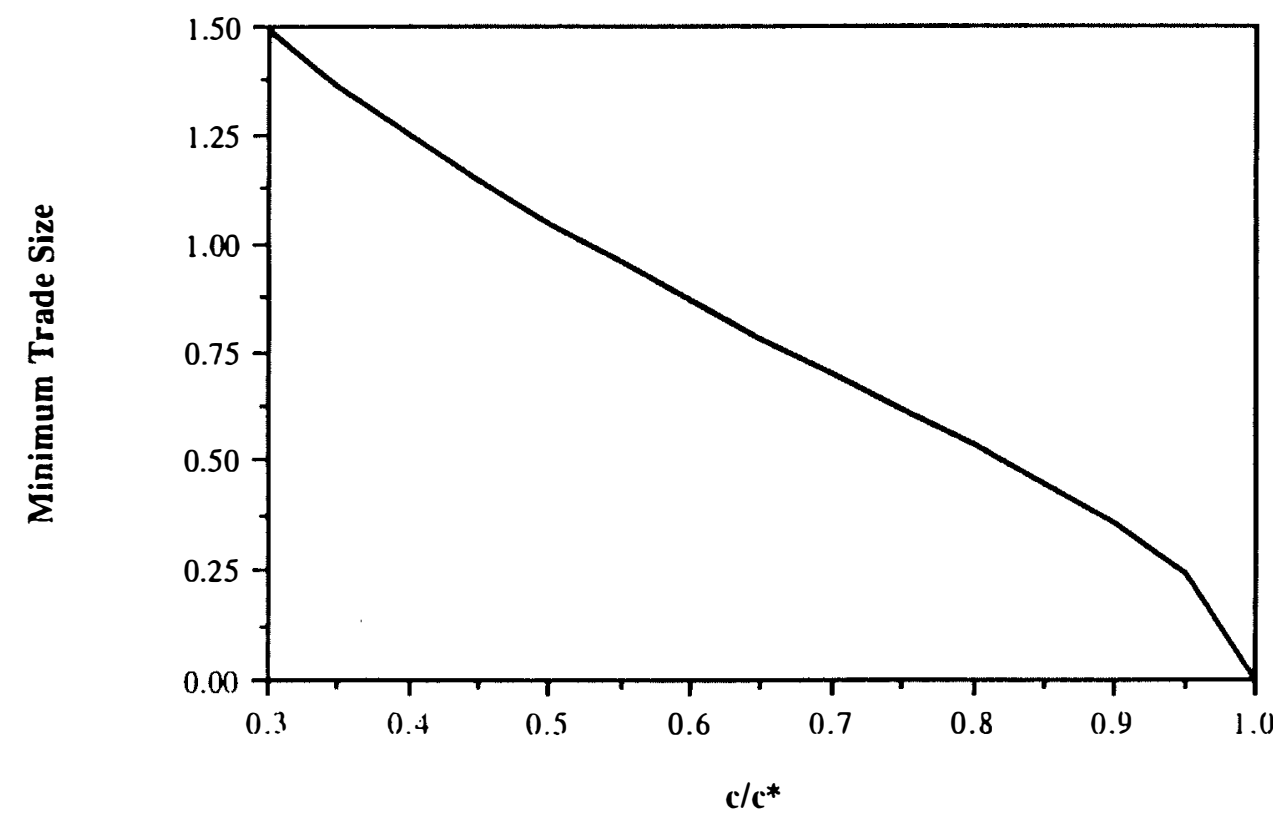

As trading costs a initi: in relative to acquisitina custis. $\omega^{*} \rightarrow 0$. 
Figure 9: Trading Cost vs. Trade Size, Different Txn Costs

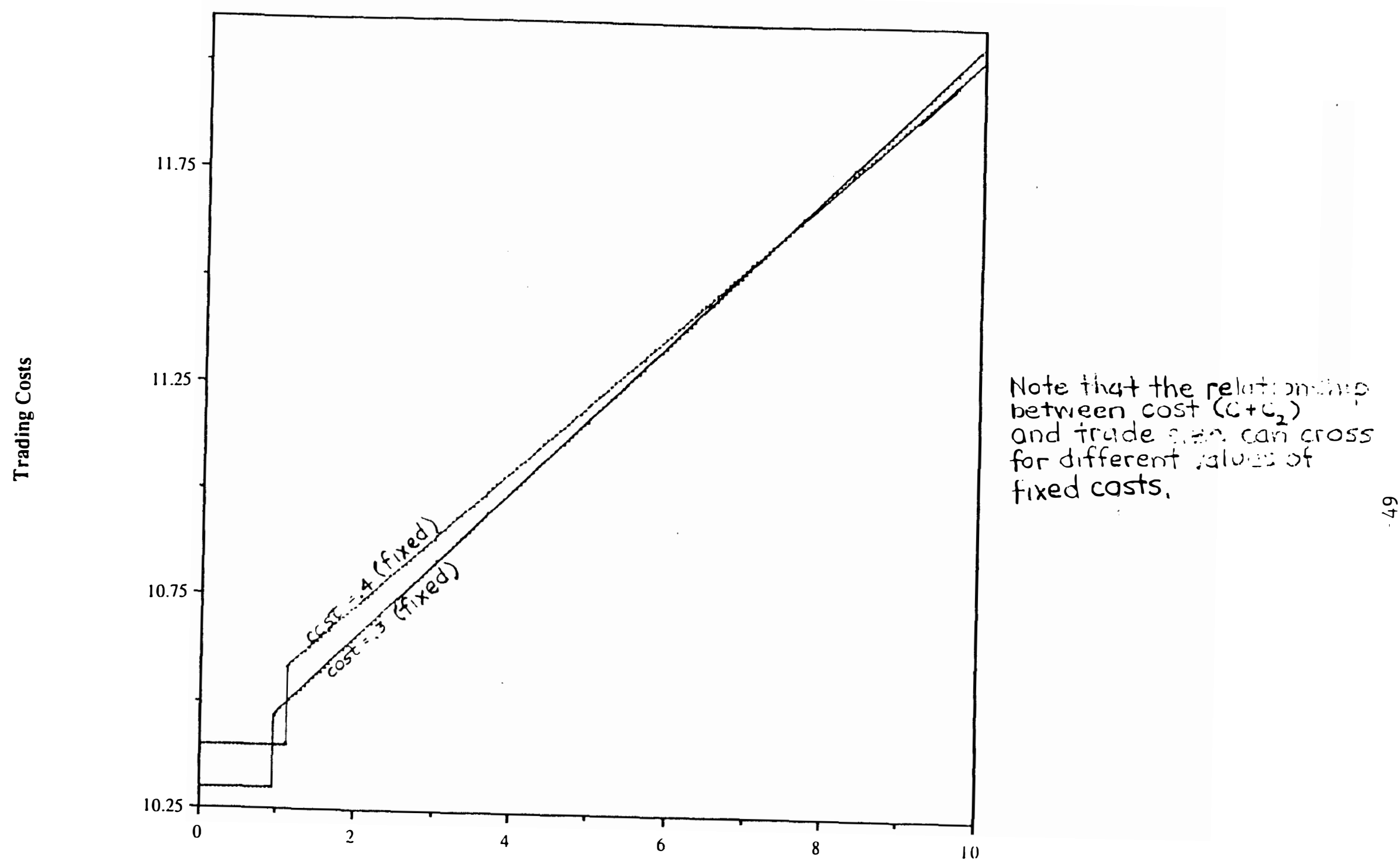


Sount

Figure 10a: Alcoa Trading Frequency (volume $<1000$ )

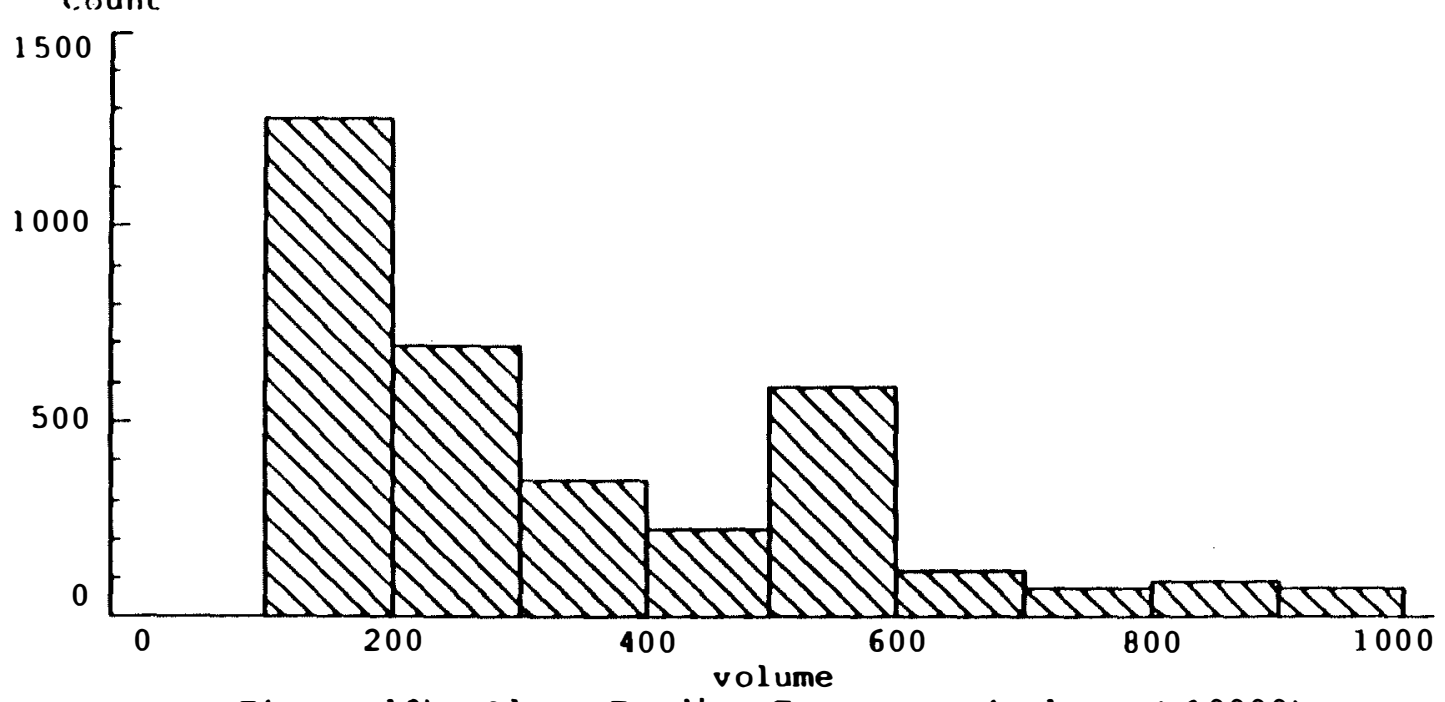

Count Figure lob: Alcoa Trading Frequency (volume < 10000)

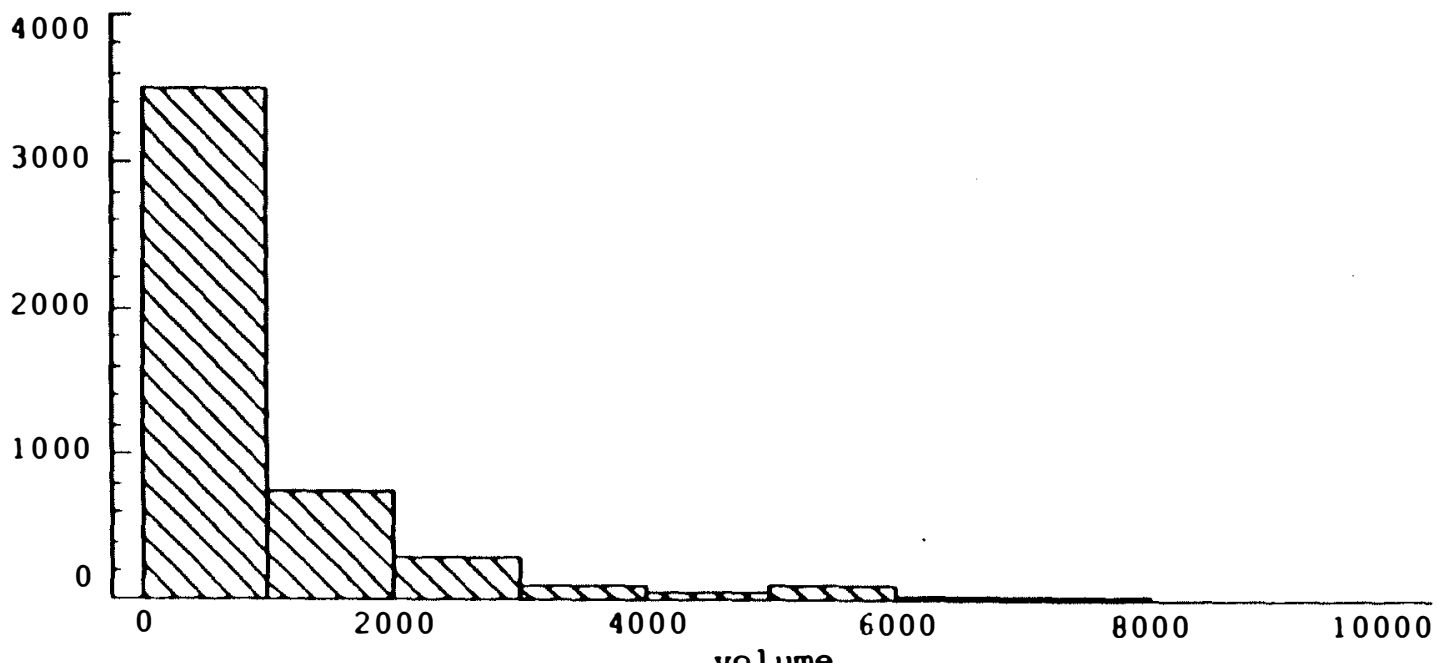




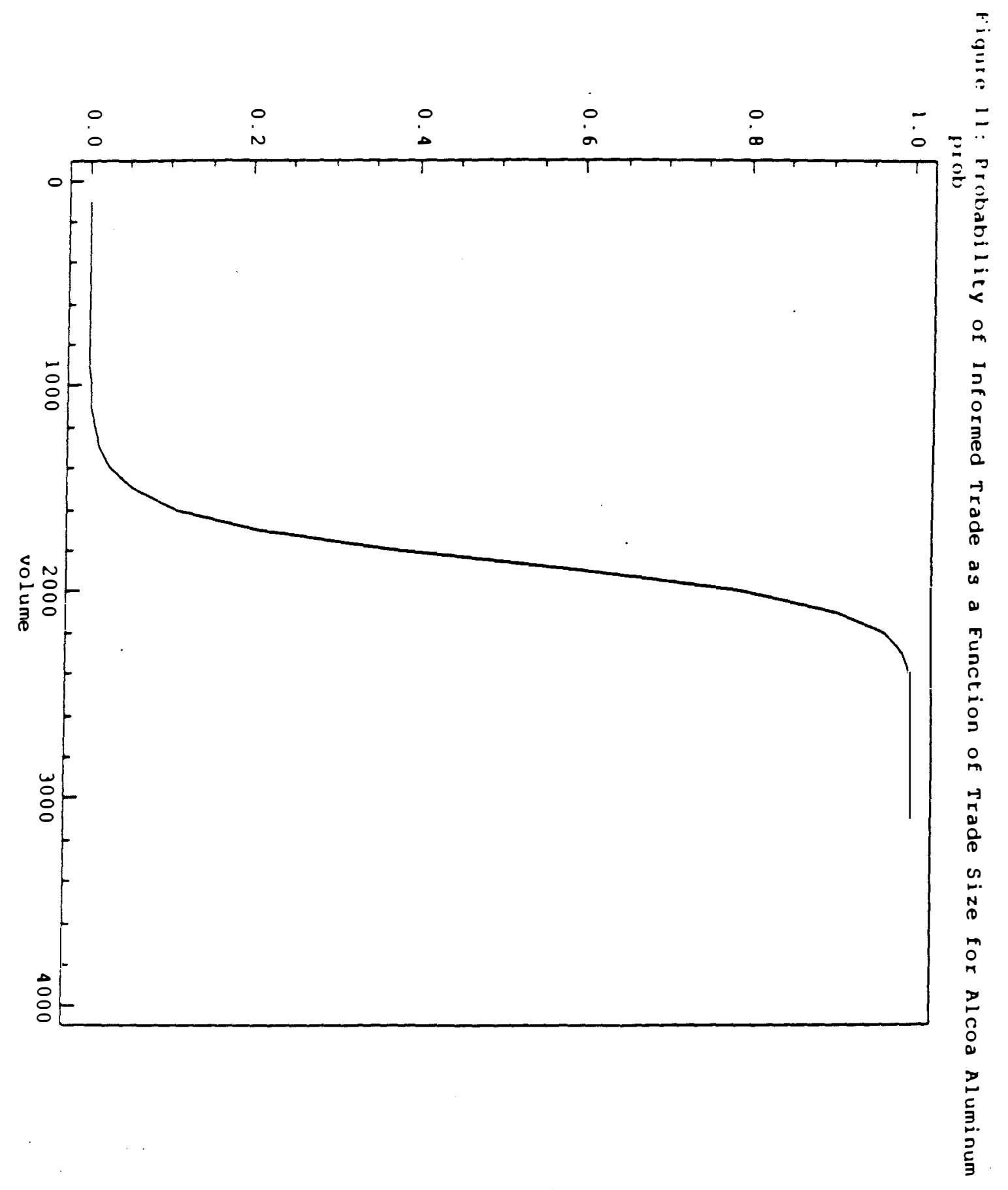

